\title{
Are Anxiety Disorders Associated with Accelerated Aging? A Focus on Neuroprogression
}

\author{
Giampaolo Perna, ${ }^{1,2,3}$ Giuseppe Iannone, ${ }^{1}$ Alessandra Alciati, ${ }^{1}$ and Daniela Caldirola ${ }^{1}$ \\ ${ }^{1}$ Department of Clinical Neurosciences, Hermanas Hospitalarias, FoRiPsi, Villa San Benedetto Menni, Albese con Cassano, \\ 22032 Como, Italy \\ ${ }^{2}$ Department of Psychiatry and Neuropsychology, Faculty of Health, Medicine and Life Sciences, Maastricht University, \\ 6200 MD Maastricht, Netherlands \\ ${ }^{3}$ Department of Psychiatry and Behavioral Sciences, Leonard Miller School of Medicine, Miami University, Miami, FL 33136, USA \\ Correspondence should be addressed to Giampaolo Perna; pernagp@gmail.com
}

Received 6 August 2015; Revised 5 October 2015; Accepted 8 October 2015

Academic Editor: James M. Wyss

Copyright (C) 2016 Giampaolo Perna et al. This is an open access article distributed under the Creative Commons Attribution License, which permits unrestricted use, distribution, and reproduction in any medium, provided the original work is properly cited.

\begin{abstract}
Anxiety disorders (AnxDs) are highly prevalent throughout the lifespan, with detrimental effects on daily-life functioning, somatic health, and quality of life. An emerging perspective suggested that AnxDs may be associated with accelerated aging. In this paper, we explored the association between AnxDs and hallmarks of accelerated aging, with a specific focus on neuroprogression. We reviewed animal and human findings that suggest an overlap between processes of impaired neurogenesis, neurodegeneration, structural, functional, molecular, and cellular modifications in AnxDs, and aging. Although this research is at an early stage, our review suggests a link between anxiety and accelerated aging across multiple processes involved in neuroprogression. Brain structural and functional changes that accompany normal aging were more pronounced in subjects with AnxDs than in coevals without AnxDs, including reduced grey matter density, white matter alterations, impaired functional connectivity of large-scale brain networks, and poorer cognitive performance. Similarly, molecular correlates of brain aging, including telomere shortening, $\mathrm{A} \beta$ accumulation, and immune-inflammatory and oxidative/nitrosative stress, were overrepresented in anxious subjects. No conclusions about causality or directionality between anxiety and accelerated aging can be drawn. Potential mechanisms of this association, limitations of the current research, and implications for treatments and future studies are discussed.
\end{abstract}

\section{Introduction}

Anxiety disorders (AnxDs) are highly prevalent across the lifespan in the general population. Pooled 1-year and lifetime prevalence have been estimated at around $11 \%$ and $17 \%$, respectively [1]. Different AnxDs are more prevalent at specific lifespan stages. Phobias predominate in childhood, panic disorder (PD) predominates in adulthood, and generalized anxiety disorder (GAD) and agoraphobia (AG) predominate in adulthood and older age. AnxDs can also have a late onset, with an incidence of 3-4\% after 55-60 years of age [2-4].

AnxDs are chronic and stressful conditions that can negatively affect quality of life, somatic health, and cognitive performance. Several studies documented that anxiety is a risk factor for many age-related medical conditions, such as coronary heart disease, diabetes, and disability, as well as for global mortality [5-7]. Recent findings showed an association between AnxDs or anxiety symptoms and reduced verbal memory, language, and executive functions in older individuals without dementia [8-11].

An emerging perspective suggested that in people with AnxDs decreased somatic health or cognition may partly result from accelerated cellular aging and neuroprogression. Neuroprogression is pathological reorganization of the central nervous system (CNS), along the course of severe mental disorders, leading to cerebral structural changes and functional alterations. It is a combination of increased neurodegeneration, neuronal apoptosis or neurotoxic susceptibility, and lowered neuroplasticity [12]. Neuroplasticity refers to the ability of the brain to modify itself in response 
to environmental demands and it plays an important role in optimizing brain functionality. It encompasses neurogenesis, structural and functional brain reorganization, cellular and molecular changes, and cognitive plasticity [13]. These processes occur throughout the lifespan in response to a wide array of genetic and environmental factors. Neuroplasticity is downregulated in adulthood and old age and its impairment can negatively impact successful aging [14] and cognitive performance [15]. Neuroprogression has been extensively investigated in major depressive disorder (MDD)/bipolar disorder (BD) and several potential mechanisms of neuroprogression have been proposed, including immune-inflammatory and oxidative/nitrosative stress with its concomitants and sequels, dysregulation of the hypothalamic-pituitary-adrenal (HPA) axis, autonomic nervous system (ANS), and immune system or neurotransmitters' functioning (for detailed reviews, see $[12,16-19])$. This research on AnxDs is at the early stage. However, some neuroprogressive pathways found in MDD/BD may be present also in subjects with AnxDs and contribute to accelerated aging and neuroprogression in this population [20].

In this paper, we reviewed evidence of an association between AnxDs, according to DSM-5 criteria [21], and hallmarks of accelerated aging, with a focus on neuroprogression. Thus, we explored, in animal and human studies, the overlap between processes of neurogenesis, neurodegeneration, structural, functional, molecular, and cellular modifications in AnxDs, and aging. To the best of our knowledge, no reviews on this issue have been published.

\section{Materials and Methods}

This is a nonsystematic review. Data were sourced from PubMed electronic database and were not limited by date of publication. Only articles written in English language were considered.

\section{Neurogenesis}

Neurogenesis refers to the formation, growth, and development of new neurons from neural stem cells and progenitor cells. Adult neurogenesis in humans is restricted to the hippocampus (subgranular and subventricular zones of the dentate gyrus) [22-24].

3.1. Impaired Neurogenesis in Anxiety. Adult hippocampal neurogenesis (AHN) is impaired in rodent models of anxiety, including chronic unpredictable mild stress, repeat restraint stress, social defeat stress, and corticosterone administration, as well as in models of social stress in nonhuman primates, such as the intruder stress and social isolation models. These paradigms trigger anxiety- and depression-like behaviors in animals, suggesting a possible association between both anxiety and depression and altered AHN [25]. In rodent models of childhood neglect (which is a risk factor for future anxiety and mood disorders in humans), young rats separated from their mothers exhibited both increased anxiety and decreased AHN in adulthood [26]. Recently, decreased hippocampal number of neuroblasts and dendritic arborization related to high corticosterone were found in Carioca HighConditioned Freezing rats, an animal model of generalized anxiety disorder (GAD) [27]. Transgenic mice in which AHN was impaired exhibited significant increased anxietylike behavior [28, 29]. Finally, in rodents, disrupting AHN negatively affected pattern separation, which is the learning process by which similar experiences are transformed into distinct, nonoverlapping representations [30]. Since pattern separation impairment seems to be implicated in overgeneralization of conditioned fear in AnxDs, an association between reduced AHN and anxiety may exist in humans [31]. Both in stressed rodents [32] and in nonhuman primates, antidepressants, which are the first-line treatment for AnxDs, increase AHN which, in turn, can diminish anxiety-like behavior [33-35].

No published postmortem brains studies have directly or indirectly measured AHN in humans with AnxDs. Highresolution MRI volumetric studies showed smaller dentate gyrus size in subjects with anxiety [25], but the extent to which this may be related to changes in AHN or to other forms of structural plasticity remains to be determined. Finally, no studies are available on the relationship between medications and AHN in individuals with AnxDs.

In summary, animal models showed that altered neurogenesis may be associated with anxiety, but whether accelerated AHN impairment is also related to human anxiety remains an open issue. In clinical samples, direct $\mathrm{AHN}$ assessment is needed, and new noninvasive measurements of AHN in humans, such as by SPECT or MRI, are emerging [36, 37]. In light of preclinical data and given that multiple biological alterations in people with AnxDs, including higher levels of corticosteroids [38], and proinflammatory factors [39] and/or lower levels of growth factors [40] have well-known detrimental effects on AHN [41, 42], this field is worth of being further investigated.

3.2. Impaired Neurogenesis in Aging. In animal studies, aging has been associated with significant decline in adult hippocampal neurogenesis (AHN) in rodents $[43,44]$, canines [45], and marmosets [46]. Several studies showed that AHN in rats decreases by $80 \%$ by about one-two years of age [47-49]. Also, in humans, the formation of new neurons is abundant during infancy and adolescence and dramatically decreases during adulthood and especially in old age. Although decreased neurogenesis may exert important protective effects, such as tumor prevention [50], it seems also to be linked to cognitive flexibility impairment in mice [51] and age-related cognitive deficits in humans [52].

In conclusion, preliminary evidence suggests that anxiety may be associated with decreased neurogenesis, similar to what has been observed during aging.

\section{Brain Structural Changes}

4.1. Brain Structural Changes in Anxiety. In murine models, hippocampal volume and trait anxiety were inversely related [53], and stress-related hypercortisolemia or chronic treatment with corticosterone resulted in hippocampal atrophy and anxiety-like behaviors $[54,55]$. In nonhuman primates, 
high trait-like anxiety has been associated with smaller volume of the dorsal anterior cingulate cortex (dACC), which is a portion of the prefrontal cortex (PFC) [56]. In humans, several structural neuroimaging studies compared people with AnxDs to healthy controls. In subjects with panic disorder (PD), reduced volume of the temporal lobe, as well as reduced gray matter (GM) density in the amygdala and hippocampus, was found. GM abnormalities have also been found in the bilateral putamen, left orbitofrontal cortex, inferior frontal cortex, superior temporal gyrus, right insula, and anterior cingulate cortex $[57,58]$. In GAD, decreased structural connectivity between the amygdala, the anterior cingulate cortex (ACC), and the PFC was found. Other studies showed reduced hippocampal volume, decreased white matter (WM) in the ACC and middle cingulated cortex integrity, and decreased GM volumes in the precentral gyrus, precuneus, orbitofrontal gyrus, and posterior cingulate gyrus [59]. Disrupted WM microstructure coherence of the right splenium and right parietal cortex was also found [60]. Finally, preliminary investigation showed altered structural brain connectivity in patients with social anxiety disorder (SAD) suggesting frontal WM alteration in or near the uncinate fasciculus, a structure that connects anterior temporal areas with prefrontal/orbitofrontal cortices [61].

4.2. Brain Structural Changes in Aging. Brain structural alterations accompany normal aging. SAMP10 mice, a strain of inbred mice developed to study human aging, exhibited age-related cortical atrophy in the frontal cortex, occipital lobes, olfactory bulbs, amygdala, and entorhinal cortex [62]. In humans, postmortem and structural neuroimaging findings showed age-related brain atrophy $(0.4-0.5 \%$ brain tissue loss per year), as indicated by reduced brain volume and weight, ventricular expansion, and sulcal enlargement [63]. Prominent age-related GM loss has been demonstrated both cross-sectionally and longitudinally in the frontal and prefrontal areas, hippocampus, temporal and parietal cortices, amygdala, and cerebellum and was accompanied by shrinkage and dysmorphology of neurons and deafferentation and reduction in synaptic density [64-69]. Structural WM degeneration occurs in the entire brain and mainly in the frontal cortex [70, 71]. Both GM and WM structural alterations are likely to impair communication within and between brain areas and lead to age-related cognitive decline [72].

In conclusion, anxiety has been associated with several brain structural changes, some of which are similar to those observed during aging.

\section{Brain Functional Changes}

Functional connectivity reflects the quality of information transfer and functional communication between brain areas that increase or decrease their activity synchronically. Among these, a network of brain regions plays a relevant role during resting states: the default-mode network (DMN) (i.e., the "task-negative" network) that consists of the precuneus/posterior cingulate cortex (PCC), medial prefrontal cortex, medial temporal regions, medial, lateral, and inferior parietal cortex, and portions of the ACC, and it is active during internally directed mental states, such as introspective states, remembering, planning, and related cognitive functions, and emotion regulation. The DMN is connected with the "task-positive" network that consists of the dorsolateral prefrontal cortex, inferior parietal cortex, and supplementary motor area and it is associated with task-related patterns of increased attentional orientation and response preparation [73].

5.1. Brain Functional Changes in Anxiety. Impaired functioning of several brain networks involved in cognition and motivation has been found in subjects with anxiety. Individuals with different AnxDs (in particular GAD and $\mathrm{SAD}$ ) or with high trait anxiety presented decreased functional connectivity among areas of the cinguloopercular and frontoparietal networks compared to controls, resulting in impaired detecting errors/conflicts and cognitive control to resolve future conflicts. Functional changes within the frontoparietal network and between the cinguloopercular and frontoparietal networks and the amygdala were also found [74]. Decreased functioning of the DMN [74] and its functional connectivity with the amygdala has been observed in subjects with AnxDs compared to healthy controls [75, 76]. A recent study comparing subjects with GAD and healthy controls indicated that the presence of GAD, longer duration of illness, and symptoms severity exacerbated the effects of age on decreased functional connectivity in the DMN, in particular between the posterior cingulate and the medial prefrontal cortex and between the PCC and the medial prefrontal cortex [77].

5.2. Brain Functional Changes in Aging. Normal aging is characterized by disrupted coordination of these large-scale brain systems, which may be partly responsible for the cognitive decline during aging. These brain regions are particularly vulnerable to atrophy and amyloid deposition [78]. Poorer cognitive performance in the elderly seems to be a consequence of both increased lateralized intranetwork and decreased internetwork connectivity, which may result in more diffuse and less specialized patterns of functional connections that negatively impact cognition [79-82]. Indeed, in healthy older individuals, several brain imaging studies showed decreased functional connectivity across several regions of the DMN, both at rest and during cognitive tasks, which was associated with impaired performance in processing speed, memory, and executive functions [83-86].

In conclusion, preliminary evidence suggests an association between anxiety and impaired functional connectivity, similar to what has been found during aging.

\section{Cognitive Decline}

6.1. Cognitive Decline in Anxiety. Both animal and human studies suggested that anxiety may be associated with cognitive changes similar to those observed during normal aging. In mutant mice, anxiety correlated with impaired spatial learning and memory [87]. Transgenic mice with higher levels of corticosterone (an animal model reproducing 
hyperactivity of the HPA axis, which is often seen in AnxDs) exhibited learning and memory plasticity deficits [88]. In tree shrews stressful experiences increasing cortisol levels resulted in declarative memory deficits that persisted several weeks afterward despite rebound cortisol levels [89]. Neuropsychological studies on individuals with AnxDs yielded mixed results, probably because of different sampling, methodology, neuropsychological test batteries, and lack of control for confounding variables, such as pharmacological treatments. Preliminary findings suggested that subjects with GAD have poorer performance in processing speed, verbal memory, working memory, cognitive flexibility, and executive functions compared to healthy controls [90-92]. Individuals with $\mathrm{PD}$ or SAD exhibited poorer verbal memory, attention, learning, and executive functions [93-98]. In late-life major depressive disorder comorbid AnxDs were associated with greater memory decline at 4-year follow-up [99]. In a sample of older individuals without dementia, anxiety symptoms were associated with memory loss and predicted both cognitive decline and daily-life functioning impairment after 3 years [100]. Anxiety symptoms occurred more frequently in persons with mild cognitive impairment (MCI) than in cognitively intact elderly individuals from the general population and significantly increased risk of progression from MCI to Alzheimer's disease at 3-year follow-up [101]. Finally, in a prospective cohort study of individuals aged 65 to 96 years, incident cognitive impairment was associated with baseline AnxDs in men and with anxiety symptoms in women, independently of depression [102].

6.2. Cognitive Decline in Aging. Advanced aging is accompanied by cognitive decline that is related to structural and functional changes [103]. In healthy older individuals, maintenance of both higher cortical volume and WM complexity has been associated with successful cognitive performance. In the elderly, strong correlations emerged between hippocampal volume and global cognition and memory, between frontal areas volume and executive function [104, 105], and between WM complexity and information processing speed, auditoryverbal learning, and reasoning [106]. Reduced mental speed [107], executive function [108], and episodic memory [109] were found whereas verbal ability and word knowledge were often maintained [110]. As previously described, diminished functional connectivity across several regions of DMN during aging is associated with progressive cognitive decline in several cognitive domains, including attention, concentration, processing speed, memory, and executive functioning [83-85]. The age-related reduced ability to decrease DMN activity when attention is required seems particularly relevant to cognitive and goal-directed activity impairment [111].

In conclusion, AnxDs and aging seem to share reduced cognitive abilities that may be related to the similar structural and/or functional brain changes described above.

\section{Beta-Amyloids}

Beta-amyloids $(\mathrm{A} \beta)$ are protein fragments implicated in neurodegeneration, cellular aging, and cognitive deterioration $[112,113]$. At high concentrations, $\mathrm{A} \beta$ can negatively influence AHN [114], synaptic functions, and monoaminergic transmission and can have cytotoxic effects and functional antagonism with brain-derived neurotrophic factor (BDNF) $[112,113]$.

7.1. Beta-Amyloids in Anxiety. In animal studies, a relationship between anxiety and $\mathrm{A} \beta$ levels was found. Stresslevel glucocorticoids administration in mice increased $\mathrm{A} \beta$ production and augmented tau accumulation, suggesting that glucocorticoids, which are also implicated in human AnxDs, may be related to $\mathrm{A} \beta$ pathology and development of neurofibrillary tangles (i.e., two neuropathological hallmarks of Alzheimer's disease and severe cognitive decline) [115]. Similarly, behavioral stressors (social isolation over 3 months or acute restraint stress) increased $A \beta$ levels in the brain interstitial fluid, hippocampus, and cortex of mice via corticotropin-releasing factor [116]. Cerebral injection of $A \beta$ fragment in rats exerted profound negative effects on the hippocampus and amygdala and induced both anxiety-like behaviors and memory impairment $[117,118]$.

Human research on this topic is scant. In middle-aged and older nondemented adults, a PET study found significant associations between trait anxiety symptoms and amyloid senile plaques and tau neurofibrillary tangles in the posterior cingulate of subjects with mild cognitive impairment (MCI) and in the medial temporal and frontal areas of subjects with no cognitive deficits [119]. In subjects with MCI, a significant association was found between $\mathrm{A} \beta 42$ and $\mathrm{t}-$ tau abnormal concentrations in the cerebrospinal fluid and anxiety symptoms severity [120]. Finally, in a prospective cohort of healthy older adults, anxiety symptoms seem to moderate, with a dose-effect relationship, the negative effects of $A \beta$ on global cognition, resulting in more rapid decline in several cognitive domains $[121,122]$.

7.2. Beta-Amyloids in Aging. In rhesus monkeys, a significant age-related $\mathrm{A} \beta$ increase was found in the basal forebrain cholinergic neurons [123]. Human PET studies showed that about one-third of healthy elderly individuals manifested elevated levels of $\mathrm{A} \beta$ deposition in the frontal, cingulated, and parietal areas and in the $\mathrm{DMN}$, even years before clinical cognitive deficits $[124,125]$. While some studies failed to report significant associations between amyloid deposition and cognitive decline [126], others found that greater amyloid deposition was negatively related to episodic memory performance and decline in healthy older adults [127-131]. A very recent study [132] showed that normal elderly individuals with high $\mathrm{A} \beta$ plasma levels presented lower cognitive performance and thinner cortex than those with low $\mathrm{A} \beta$ levels.

In conclusion, the available findings suggest an association between anxiety and $\mathrm{A} \beta$ pathology and indicate that this is a critical topic worth of future investigation.

\section{Telomere Shortening}

Telomeres are specialized DNA-protein complexes found at the ends of chromosomes. Small portions of telomeric DNA are normally lost with time and cell division: when telomeres 
get too short, the cell can no longer divide and eventually dies. Telomere shortening is progressive with age and is considered a biomarker of cellular aging/damage and disease [133].

8.1. Telomere Shortening in Anxiety. Both animal and human findings showed an association between anxiety and telomere shortening. Deficiency of telomerase (i.e., an enzyme that preserves telomere length by adding telomeric DNA) resulted in increased anxiety-like behavior in aged transgenic mice when compared with wild-type mice [134]. In human nonpsychiatric samples, associations were found between exposure to chronic stress (e.g., childhood adverse experiences/stressful caregiving status) or high phobic anxiety and accelerated telomere shortening, which may be related to dysregulation of inflammatory markers, HPA axis, and autonomic system function [135-138]. Longitudinal findings demonstrated that AnxDs predicted shorter leukocytes telomeres at 2 years of follow-up in the general population, whereas depressive disorders did not [139], and persistence of internalizing psychiatric disorders, including GAD, from adolescence to adulthood, predicted shorter telomere length at age 38 [140]. Patients with current AnxDs, but not remitted, had shorter leukocyte telomeres compared to healthy controls [20], suggesting that telomere shortening may be partly reversible. Furthermore, anxiety symptoms severity was associated with telomere shortening in the whole sample, suggesting a dose-response association, similar to what was found by Okereke and coworkers [138]. Young women with GAD or PD had shorter telomeres than women with no GAD or PD [141] and older subjects with AnxDs had significantly shorter telomeres than coeval healthy controls [142], suggesting that anxiety may accelerate age-related telomere shortening.

8.2. Telomere Shortening in Aging. Telomere shortening increases with age [133]. Preclinical studies demonstrated that insufficient telomerase activity impairs telomere length restoration, enhancing susceptibility to cellular senescence and death [143]. In adult and old mice with critically short telomeres, dietary supplementation of the telomerase activator TA-65 increased average telomere length and improved many health-span indicators [144].

Human studies also point to a causal relationship between telomere shortening and increased risk of age-related disease, including cancer, diabetes, and coronary heart disease [143, $145,146]$. Since cell or tissue dysfunction is triggered by severe telomere shortening, telomerase activation may promote health maintenance. In humans telomere shortening can be also delayed by telomerase activator dietary supplementation [147] which enhanced several indicators of metabolic, bone, and cardiovascular health (e.g., glycemia, cholesterol, and blood pressure) at 5-year follow-up [148]. Telomeres seem to be involved in neurodegeneration and neurodegenerative diseases as well. Molecular mechanisms of neurodegeneration, such as abnormal levels of $\mathrm{A} \beta$, may accelerate neuronal senescence through telomere attrition [149]. An association between shorter telomeres and poorer cognitive performance has been observed in general elderly populations, suggesting that telomere length may serve as a biomarker of cognitive aging [150,151]. Telomere shortening is modulated by both genetic and nongenetic factors, including oxidative stress, inflammation, physical activity, and lifestyle $[150,151]$.

In conclusion, anxiety may be related to shorter telomeres which also characterizes aging and age-related diseases and cognitive decline.

\section{Activated Immune-Inflammatory Pathways}

Activated immune-inflammatory pathways are considered "core" components of neuroprogressive changes [17]. Cellmediated immunity (CMI) involves activation of T cells that produce cytokines such as IFN- $\gamma$ and IL-2, which activate monocytes/macrophages. In turn, monocytes/macrophages produce several cytokines such as IL-1 $\beta$ (exerting a positive feedback loop on T cells), IL-12 (triggering T cells to produce more IFN- $\gamma$ ), TNF- $\alpha$, IL-6, and IL-8. Inflammation consists of cellular, cytokine, and complement cascades and an acute phase response. Macrophage-derived cytokines, known as proinflammatory cytokines (PICs), mediate inflammation by enhancing the positive acute phase proteins (APPs), for example, C-reactive protein (CRP) and haptoglobin, and lowering the negative APPs, for example, albumin and transferrin. During inflammation, also counter-antiinflammatory mechanisms become active (e.g., increased production of the IL-1 receptor antagonist) to dampen the primary inflammatory response $[12,152]$. Activated immuneinflammatory pathways increase oxidative/nitrosative processes [153] (Figure 1).

9.1. Activated Immune-Inflammatory Pathways in Anxiety. Preclinical and human studies suggested that anxiety is associated with CMI activation and inflammation. Although results are mixed [154], some animal studies showed a relationship between increased proinflammatory cytokines levels including interleukin-6 [155] and IL-1 $\beta$ [156] and anxietylike behaviors. In mice, sustained inflammatory pain, with concomitant TNF- $\alpha$ increase in basolateral amygdala, was associated with anxiety-like behaviours which was reversed by local infusion of infliximab, a TNF- $\alpha$ neutralizing antibody [157]. In humans, significantly increased levels of proinflammatory cytokines have been detected in patients with AnxDs compared to nonanxious subjects, independently of sociodemographic features and depressive symptoms $[39,158]$. Higher inflammatory dysregulation was especially found in persons with late-onset AnxDs [159]. Recently, PD has been associated with lower levels of mannan-binding lectin (MBL), an important arm of the innate immune system, the deficiency of which may result in infections or autoimmune diseases [160]. Plasma anti-serotonin and serotonin anti-idiotypic antibodies are elevated in PD compared to healthy controls, suggesting a link between autoimmune mechanisms and AnxDs [161]. In the general population, anxiety symptoms were associated with increase of several inflammation markers, including C-reactive protein, TNF$\alpha$, and IL-6, even after adjusting for multiple confounding factors [162].

Activated immune inflammation may be related to anxiety also through its influence on serotoninergic pathways. 


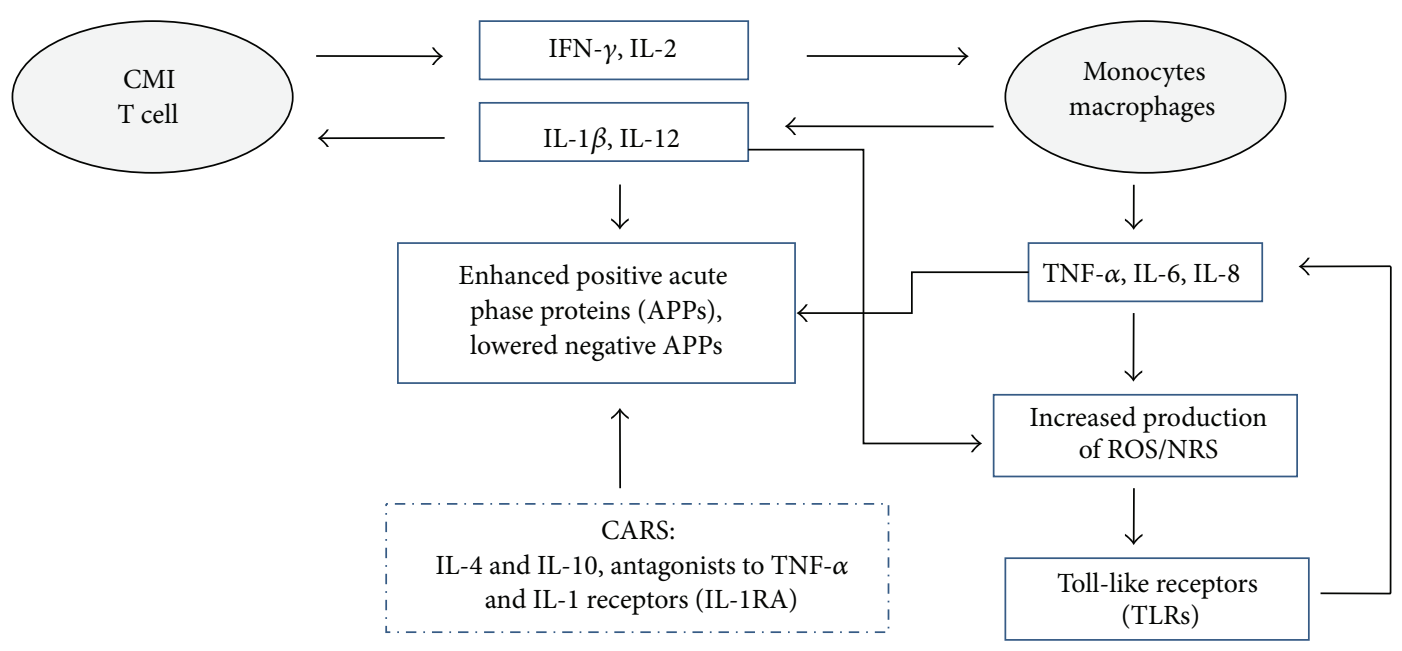

FIGURE 1: Relationship between activated immune-inflammatory pathways and oxidative/nitrosative stress (O\&NS). CMI involves activation of T cells that produce cytokines such as IFN- $\gamma$ and IL-2, which activate monocytes/macrophages. Monocytes/macrophages produce IL- $1 \beta$ and IL-12 (that exert a positive feedback loop on T cells), as well as TNF- $\alpha$, IL-6, and IL-8. Proinflammatory macrophage-derived cytokines (PICs) mediate inflammation enhancing the positive acute phase proteins (APPs), for example, C-reactive protein, and lowering the negative APPs, for example, albumin. The counterinflammatory response syndrome (CARS) tends to dampen the acute inflammatory response producing IL-4 and IL-10 (responsible for decreasing TNF- $\alpha$, IL-1, IL-6, and IL-8) and the antagonists to TNF- $\alpha$ and IL-1 receptors (IL-1RA), which inactivate the cytokine or block the receptors. Immune inflammation and O\&NS influence each other. Inflammatory and CMI responses are accompanied by increased production of reactive oxygen species (ROS) and reactive nitrogen species (RNS) while oxidative stress maintains inflammation mainly through the activation of toll-like receptors (TLRs). Damaged macromolecules released during condition of oxidative stress can activate TLRs which produce an inflammatory response whose key mediators are IL-1, IL6, and TNF- $\alpha$. CMI: cell-mediated immune; IL-6: interleukin-6; IL-1 $\beta$ : interleukin-1 $\beta$; IL-12: interleukin-12; TNF- $\alpha$ : tumor necrosis factor- $\alpha$; IFN- $\gamma$ : interferon- $\gamma$; APPs: acute phase proteins; TLRs: toll-like receptors.

During CMI activation, cytokines, mainly IFN- $\gamma$, induce indoleamine 2,3-dioxygenase (IDO) [163] which, in turn, stimulates the catabolism of tryptophan leading to its plasma depletion and synthesis of tryptophan catabolites (TRYCATs). The TRYCATs kynurenine and quinolinic acid induced anxiety-like behaviours in animal models [164]. In humans, a correlation between plasma kynurenine concentration and caffeine-induced anxiety has been found [165]. Several studies suggested a relationship between activated immune- inflammatory pathways and increased intestinal permeability, called leaky gut [166]. It is characterized by the weakening of the tight junctions' barrier, formed by epithelial cells, which segregates the luminal bacteria in the gut, and can be produced by inflammatory processes [167] and/or by oxidative stress [168]. When leaky gut is present, Gram-negative bacteria or lipopolysaccharide (LPS), a component of the outer membrane of Gram-negative bacteria, is translocated from the gut to mesenteric lymphonodes and, consequently, CMI activation with cytokines release may be elicited. Gut-derived bacterial products, such as LPS, can induce anxiety-related behaviors (e.g., reduced exploratory behavior and social interactions) when administered to rodents [169-171] and cause acute anxiety and cognitive deficits in healthy male volunteers [172]. In line with this, recent animal studies showed that diet-induced changes in the gut microbiota influence long- and short-term memory and cognitive flexibility in mice [173]. LPS effects could partly be related to the LPS-induced elevation of peripheral cytokine that, in turn, may affect amygdala activity [174].
Moreover, LPS-induced inflammation can enhance the IDO activity and the availability of kynurenine, which has been shown to increase anxiety when administered peripherally to mice [175]. Data on TRYCATs and leaky gut/LPS pathways in subjects with AnxDs are still lacking and future studies are warranted.

9.2. Activated Immune-Inflammatory Pathways in Aging. "Inflammaging" refers to the chronic progressive inflammatory status of the brain during aging [176]. In mice, TREM2 expression (an immune receptor involved in suppressing inflammatory responses) increased during aging [177] and protected against aging-related neuroinflammation, neuronal losses, and cognitive impairment [178]. Human investigations showed that elderly people exhibit chronically increased levels of proinflammatory cytokines and reduced levels of anti-inflammatory cytokines $[179,180]$, which correlated with memory impairment [180] and general cognitive decline [181]. In older nondemented people, MRI studies demonstrated macrostructural brain abnormalities linked to inflammation, including reduced hippocampal and GM volume, global brain atrophy, cortical thinning, and WM hyperintensity, which may partly explain the age-related cognitive decline [182-184]. Recently, an association between reduced microstructural integrity of WM pathways and higher circulating inflammatory markers (i.e., C-reactive protein and tumor necrosis factor-alpha, TNF- $\alpha$ ) was found in middleaged and elderly people, which correlated with higher-order cognitive functions impairment [182]. Neuroinflammation 
can be a cause (by generating reactive oxygen and nitrogen species) or a consequence of chronic oxidative stress (OS). Over time, OS triggers a self-perpetuating cycle of chronic neuroinflammation inducing even more OS, leading to neuronal degeneration and cell death [185]. Finally, aging effects on gut microbiota may induce a higher propensity to develop the Clostridium difficile infection which enhances local and systemic proinflammatory markers (IL-1 $\beta$, TNF- $\alpha$, and CRP) and increases the permeability of gut barrier [186].

In conclusion, anxiety seems to be associated with activated immune-inflammatory pathways, which are also a characteristic of aging.

9.3. Mechanisms by Which Activated Immune-Inflammatory Pathways May Contribute to Accelerated Aging and Neuroprogression. The immune-inflammatory pathways may contribute to accelerated aging and neuroprogression by several mechanisms. In rats, elevated IL-2 levels are associated with neurocognitive impairments, microglial activation, reactive astrogliosis, myelin damage, neuronal loss, and changes in several receptors, such as cholinergic and/or dopaminergic receptors in frontoparietal cortex and hippocampal regions $[187,188]$. By inducing IDO activation, elevated IFN- $\gamma$ may lower serotonin levels (5-HT) and increase TRYCATs, with negative effects on neuronal survival. Indeed, lower 5-HT may negatively affect neurogenesis and BDNF expression in adult mammals [189]. TRYCATs, especially quinolinic acid, may increase production of reactive oxygen species (ROS), induce mitochondrial dysfunctions, exert neurotoxic effects by acting as NMDA-receptor agonists, and cause hippocampal cell death and reduction in cerebral cholinergic circuits in rodents [190-192]. Recently, activation of the kynurenine pathway has been shown to affect hippocampal neurogenesis in humans [193]. Increased levels of IL-6 may have neurodegenerative effects in mice [194] and IL$1 \beta$ may exert neurotoxic effects with neuronal death $[195$, 196], impair hippocampal neurogenesis [197], and reduce BDNF expression [198]. TNF- $\alpha$ may potentiate glutamate neurotoxicity and silence cell survival signals [199]. LPS can cause cell death by inducing apoptosis and increasing levels of ROS and reactive nitrogen species (RNS) [200]. Finally, activated immune-inflammatory pathways are implicated in $\mathrm{A} \beta$ formation [201], telomere shortening [202, 203], and increasing of O\&NS [153] that, in turn, is highly implicated in aging and neuroprogression (see the following sections) (Figure 2).

\section{Oxidative/Nitrosative Stress}

Oxidative/nitrosative stress (O\&NS) may come from free radicals (FR) (superoxide, hydroxyl radical) or nonradical molecules, like hydrogen peroxide, and their derivatives, that is, reactive oxygen species (ROS) and reactive nitrogen species (RNS). Inflammation and mitochondrial processes are sources of ROS and RNS. Under normal conditions, the potentially damaging effects of increased ROS and RNS are counterbalanced by enzymatic and nonenzymatic antioxidant defense systems [16]. Activation of O\&NS occurs when excess of ROS/RNS and/or compromised antioxidant mechanisms are present. Consequently, O\&NS may damage cellular structures such as DNA, lipids (including omega-3 PUFAs), proteins, mitochondria, and cell membranes, up to cellular death [204]. These processes alter the endogenous fatty acids and proteins and may render them immunogenic, inducing autoimmune responses against these modified antigenic determinants (neoepitopes) that lead to a vicious circle resulting in additional cell dysfunctions or death [205]. Finally, O\&NS activates immune-inflammatory pathways [153] (Figure 1).

10.1. Oxidative/Nitrosative Stress in Anxiety. O\&NS seems to be involved in the pathogenesis of AnxDs [206]. In murine models, several paradigms inducing distress and anxiety-like behaviors resulted in decreased activity of antioxidant enzymes with increased oxidative damage to lipids, proteins, and DNA in multiple brain areas, such as the hippocampus, prefrontal cortex, and cerebellum. Gene expression and proteomic studies in various mice models of anxiety also showed connections between high anxiety and dysregulated expression of several proteins related to oxidative stress metabolisms [207]. Direct induction of high oxidative stress in rats or knockout mice models induced increased anxiety-like behaviors [207, 208], while antioxidant treatments reduced both oxidative stress markers and anxiety-like behaviors [208]. Similarly, indirect induction of oxidative stress via acute sleep deprivation caused anxietylike behaviors and memory impairment in rats [209]. In mice, deficiency of the antioxidant vitamin $\mathrm{E}$ increased oxidative stress and anxiogenic behaviors [210]. A diet rich in $\omega 3$ eicosapentaenoic acid (EPA) (an omega-3 PUFA that is located in cellular membranes, has anti-inflammatory properties, and is damaged by O\&NS [211]) reduces the development of anxiety-like behaviors in rats as well as normalizing dopamine levels in their ventral striatum [212]. Changes in mitochondrial energy metabolism and function related to O\&NS have been associated with anxiety in preclinical studies. In a trait anxiety mouse model, high anxiety-related behaviors were associated with mitochondrial dysfunction in cingulated cortex with enhanced oxidative stress lipid peroxidation and cell death [213]. Finally, anxietylike behaviors exhibited by rodents during aging may be partly due to increased oxidative stress levels [214].

Findings in humans with AnxDs are mixed, probably due to methodological differences among studies and several confounding factors that may influence oxidative markers and pathways [207]. However, most studies supported the hypothesis of a connection between anxiety and increased oxidative stress. Individuals with lower serum $\omega 3$ or with a higher $\omega 6 / \omega 3$ ratio ( $\omega 6$ has proinflammatory effects) have significantly higher stress-induced anxiety levels and TNF- $\alpha$ and IFN- $\gamma$ responses compared to those with higher serum $\omega 3$ and a lower $\omega 6 / \omega 3$ ratio $[211,215]$. In line with this, $\omega 3$ supplementation reduced inflammation and anxiety among healthy young adults who faced stressful major examination [216]. In patients with SAD [217, 218] and PD [219], increased levels of blood lipid peroxidation (a marker of oxidative stress-related cellular damage) were found. Adult subjects with PD [220], with PD, and with agoraphobia [221] 


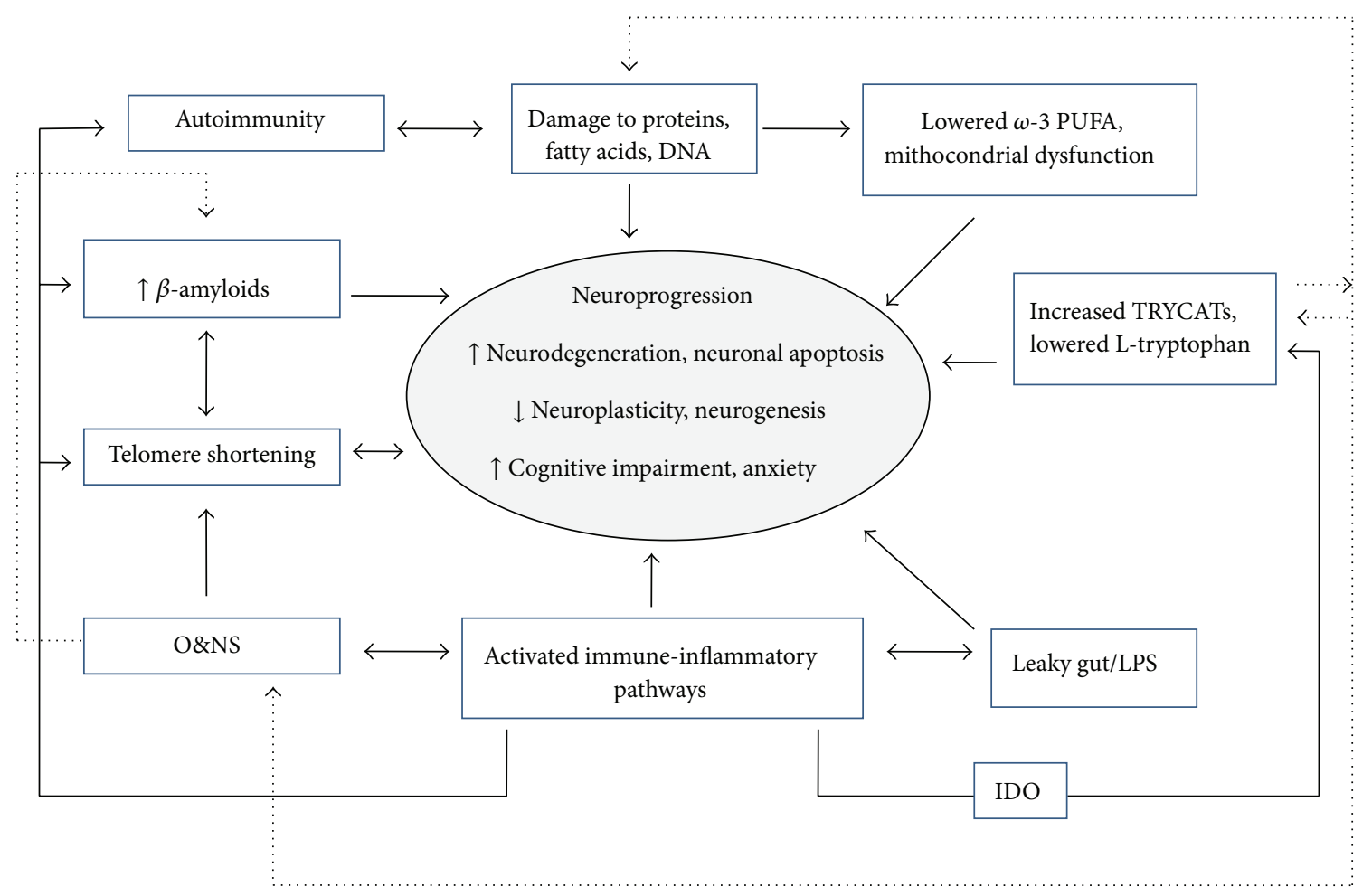

FIGURE 2: A global model of neuroprogressive changes in aging and anxiety. CMI and inflammatory responses are accompanied by activation of O\&NS with production of increased ROS/RNS. ROS/RNS can react with proteins, fatty acids (including $\omega-3$ PUFAs), and DNA and change their chemical structure which became immunogenic and produce an autoimmune response. Both O\&NS and CMI inflammation are implicated in beta-amyloid formation and telomeres shortening. Moreover, increased O\&NS impairs mitochondrial function with further production of ROS and macromolecular damage. PICs activate IDO which causes depletion of tryptophan/5-HT and the synthesis of tryptophan catabolites (TRYCATs). Some of these TRYCATs (kynurenine and quinolinic acid) are anxiogenic and neurotoxic. The lipopolysaccharide (LPS), caused by bacterial translocation from the gut, may aggravate existing inflammation and O\&NS or trigger a primary inflammatory response. LPS and lowered $\omega 3$ are associated with decreased neurogenesis. CMI: cell-mediated immune; PICs: proinflammatory cytokines; IL-1 $\beta$ : interleukin- $\beta$; IL-6: interleukin-6; TNF- $\alpha$ : tumor necrosis factor- $\alpha$; IFN- $\gamma$ : interferon-gamma; O\&NS: oxidative and nitrosative stress; ROS: reactive oxygen species; RNS: reactive nitrogen species; IDO: indoleamine 2,3-dioxygenase; TRYCATs: L-tryptophan catabolites; LPS: lipopolysaccharide (a component of the outer membrane of Gram-negative bacteria); $\omega$-3 PUFAs: omega-3 polyunsaturated fatty acids.

and children and adolescents with AnxDs [222] exhibited impaired oxidative balance and higher oxidative stress. In patients with GAD, decreased levels of the antioxidant serum free sulphydryl were found, which negatively correlated with disease duration [223]. Finally, preliminary, non-placebocontrolled studies showed that selective serotonin reuptake inhibitors (SSRIs) treatment (the first-line drug therapy for AnxDs) decreased both oxidative stress and clinical symptoms in subjects with PD and SAD [217, 220], suggesting that oxidative stress may be a state condition related to the anxious symptomatology.

10.2. Oxidative/Nitrosative Stress in Aging. O\&NS contributes consistently to aging. Animal studies showed that reducing oxidative stress/damage increased the healthy period of life [224-226], while a chronic deficit of the antioxidant vitamin $\mathrm{C}$ accelerated oxidative stress and amyloid deposition during normal aging [227]. In humans, oxidative stress has been associated with cognitive dysfunction during normal aging
[228], in mood disorders [229, 230], and in schizophrenia [231]. The O\&NS-induced damage of membrane $\omega 3$ is thought to be implicated in aging. Indeed, the $\omega 3$ eicosapentaenoic acid (EPA) has a protective effect on neurons [232] and experimental evidence indicated that $\omega 3$ docosahexaenoic acid- (DHA-) enriched diet can protect the brain from cognitive decline in aged rats [233]. In humans, a recent meta-analysis exploring the association between $\omega 3$ and risk of cognitive decline in elderly individuals has shown that daily doses from 400 to $1800 \mathrm{mg}$ (for 3-40 months) may significantly decrease the cognitive decline [234].

Finally, oxidative damage to mitochondrial functions and macromolecules are thought to play key roles in aging processes. According to the mitochondrial theory of aging [235], ROS-induced mutations of mitochondrial DNA increase over the lifespan and alter mitochondrial respiratory function leading to further increasing of ROS and damage to DNA as well as to other macromolecules, up to irreversible cellular senescence. 
In conclusion, anxiety seems to be associated with increased O\&NS, which is also implicated in processes of aging.

10.3. Mechanisms by Which Oxidative/Nitrosative Stress May Contribute to Accelerated Aging and Neuroprogression. O\&NS may contribute to accelerated aging and neuroprogression by multiple mechanisms. Damage by O\&NS involves lipid peroxidation, oxidatively induced protein and DNA alterations, altered neuronal signaling, and neuronal apoptosis [236]. O\&NS-induced lower $\omega 3$ PUFAs may be associated with decreased neurogenesis, since $\omega 3$ PUFAs have beneficial effects on serotonin metabolism stimulating neurogenesis, increase BDNF expression, and exert antiinflammatory activity $[232,237]$. O\&NS processes may also cause damage to mitochondria, which play a central role in energy production (in form of adenosine triphosphatase, ATP), are involved in metabolism of amino acids, lipids, and steroids, and regulate free radicals' levels, intracellular calcium concentration, and processes implicated in synaptic development and cell death [238]. Mitochondrial dysfunction impairs neural progenitor cell function [239] and may affect several brain functions by decreasing ATP production. Indeed, high levels of energy are needed for brain activities, including synaptic remodelling, signal transduction, and maintenance of transmembrane potential [240], and deficiency of ATP may lead to activation of the apoptotic cell death program [241]. Disrupted mitochondrial function also provokes mitochondrial-derived hyperproduction of ROS that causes a self-perpetuating cycle of O\&NS, inducing even more mitochondrial and macromolecule damage, up to neuronal degeneration and cell death [242]. Finally, O\&NS activates immune-inflammatory pathways [153], can induce accelerated telomere shortening and reduce telomerase activity $[243,244]$, and may be implicated in $\mathrm{A} \beta$ formation [245, 246] (Figure 2).

\section{Discussion}

In this paper, we explored the association between AnxDs and hallmarks of accelerated aging, with a focus on neuroprogression. We reviewed animal and human findings that suggest an overlap between processes of impaired neurogenesis, neurodegeneration, structural, functional, molecular, and cellular modifications in AnxDs, and aging. A putative global model of neuroprogressive changes in aging and anxiety is summarized in Figure 2. Although several studies pointed to a model of accelerated aging and neuroprogression for depression and bipolar disorder [12, 16, 19, 247-249], this research on AnxDs is at an early stage and some caveats should be taken into account. First, since the available data are very limited, we considered AnxDs as a group and reported findings also from nonclinical populations. However, neurobiological mechanisms implicated in the different AnxDs or in subjects with anxiety symptoms but without full-blown disorders do not completely overlap, and AnxDs differ in their incidence across lifespan [3]. Future studies are needed to investigate the specific association of each anxiety disorder with accelerated aging and whether differences exist between clinical and nonclinical populations. Second, brain imaging studies on AnxDs yielded mixed findings due to sampling, methodology, and AnxDs heterogeneity. All the same, a detailed description of these inconsistencies was beyond the scope of this paper. In line with our aim, we only reported evidence common to both anxiety and aging. Third, available animal models of anxiety are based on different theoretical constructs and to date their translational validity is still debated [250]. Thus, parallelisms between animal and human studies should be considered with caution. Fourth, multiple genetic, environmental, and individual factors may influence the biological processes involved in aging and neuroprogression, such as immune-inflammatory pathways, O\&NS, telomere shortening, and A $\beta$ generation [149]. Since the role of these confounding factors has not been exhaustively investigated, the findings of an association between these processes and the AnxDs should be considered with prudence. Finally, most studies were cross-sectional; thus, it was not possible to clarify any causal path between anxiety and aging. Considering these limitations, our review suggests a link between anxiety and accelerated aging across multiple processes involved in neuroprogression. Several brain structural and functional changes that accompany normal aging were more pronounced in subjects with AnxDs than in coevals without AnxDs, including reduced GM density, WM alterations, impaired functional connectivity of largescale brain networks (in particular the DMN), and poorer cognitive performance. Preliminary prospective findings suggested that, in older individuals, anxiety symptoms are risk factor for accelerated cognitive decline, independently of depression. Similarly, molecular correlates of brain aging, such as telomere shortening, $\mathrm{A} \beta$ accumulation, immuneinflammatory pathways, and O\&NS, were overrepresented in anxious subjects compared with coeval nonanxious subjects, especially when anxiety was severe and long-lasting. These preliminary results do not allow drawing any conclusion about causality or directionality between anxiety and accelerated aging, and future longitudinal studies are needed to shed some light on this issue. Several scenarios are possible: for example, (1) AnxDs may accelerate age-related molecular processes resulting in precocious brain structural changes and functional decline; (2) age-related processes may lead to AnxDs over time; (3) aging and AnxDs may reciprocally influence each other and/or may share some genetic and/or environmental factors which may increase vulnerability to both AnxDs and accelerated aging with neuroprogression. According to the first hypothesis, the sustained arousal and neurobiological sensitivity to different threats in anxious subjects might cause the prolonged activation of HPA axis and ANS, which, in turn, may result in increased immuneinflammatory and oxidative/nitrosative stress (IO\&NS) with a self-perpetuating chronic cycle leading to telomere shortening, precocious cellular aging, neurodegeneration, and impaired neuroplasticity $[137,251,252]$. On the contrary, according to the second hypothesis, age-related molecular changes and aging of the human brain may engage biological mechanisms similar to those implicated in anxiety, such as dysregulation of HPA axis, increased IO\&NS, and impaired limbic-frontal areas connectivity. Thus, age-related processes, 
in combination with environmental/genetic factors, may promote the development of at least some AnxDs in vulnerable individuals [253]. This hypothesis fits with the idea that AnxDs may be neurodevelopmental disorders occurring at different lifespan stages and with the higher prevalence of some AnxDs, such as GAD, in adulthood and older age [3]. Finally, according to the third hypothesis, mutual amplifications are likely implicated in the biological processes of anxiety and aging. Indeed, both conditions are accompanied by activation of IO\&NS pathways, which exhibit reciprocal reinforcement and, in turn, contribute to telomere shortening, accelerated aging, and neuroprogression [203, 207, 254]. Immune-inflammatory pathways are involved in both anxiety and cognitive decline, also by stimulating the HPAaxis function with cortisol release that modulates anxiety behavior and exerts detrimental effects on cognition [255].

In conclusion, preliminary evidence indicated an association between AnxDs and hallmarks of accelerated aging with phenomena of neuroprogression. Withal additional animal and human research is needed to satisfactorily elucidate these questions.

11.1. Implications for Treatment and Future Research. AnxDs are complex diseases which tend to be chronic when not adequately treated. Unfortunately, even evidence-based treatments, such as cognitive-behavioral therapy and SSRIs, are often not able to produce full remission and the rate of relapses after drug discontinuation is significant [256]. The theoretical framework of an association between accelerated senescence, neuroprogression, and anxiety may suggest some implications and strategies to fill these gaps. In addition to clinical symptoms of AnxDs, the use of biomarkers (such as inflammatory, oxidative, and telomere length markers) and cognitive assessment may help to better characterize the patients' profiles and clinical stages and allow more personalized treatments. The modifications of these markers during treatments may render the treatments more efficacious and represent reliable treatment-outcome predictors. Moreover, treatments specifically targeting these mechanisms, including both pharmacological and nonpharmacological "antiaging" interventions, may increase the rate of favorable outcomes. Indeed, preclinical studies suggested that some drugs currently used for AnxDs normalize some hallmarks of accelerated aging and exert a neuroprotective effect. In mice, alprazolam, zolpidem, and buspirone ameliorated the oxidant/antioxidant balance decreasing nitrite concentration and lipid peroxidation in the brain [257] and the SSRI fluoxetine reversed the decreased activity of telomerase in the hippocampus induced by chronic mild stress [258]. SSRIs promoted synaptic plasticity and neurogenesis in mice, probably by increasing BDNF, improved spatial memory learning [259], and facilitated learning and memory during aging [260]. In rats, treatments with antioxidants reduced both oxidative stress and anxiety-like behaviors [261] and in older animals increased serotonin levels [262]. In humans, preliminary data showed that SSRIs reversed high oxidative stress in patients with depression, PD, or SAD [217, 220, 263], promoted hippocampal neurogenesis [264] in depressed subjects, and decreased $\mathrm{A} \beta$ production in the cerebrospinal fluid of healthy individuals [265]. Finally, successful pharmacological treatment with the SSRI escitalopram in late-life GAD was associated with episodic memory and executive functioning improvement [90]. Nonpharmacological treatments may include physical activity and nutritional interventions. In mice, physical activity increased telomerase activity and cognitive performance $[266,267]$ and decreased both oxidative stress and anxiety-like behaviors [208]. In humans, physical activity increased brain volume [268] and preserved cognitive functions in healthy older adults [269], improved comorbid anxiety and executive functioning impairment [270], and has been proposed as a neuroprotective strategy with antioxidant properties [271]. Recent investigations suggested that Mediterranean dietary pattern slowed cognitive decline and improved cognitive performance [272, 273] by reducing inflammation markers [274] and oxidative damage [275]. Higher intake of processed and unhealthy foods was associated with increased anxiety in a population-based study [276], while a healthier dietary pattern was associated with a reduced likelihood of anxiety or depressive disorders [277]. Finally, improvement in both cognition and anxiety was exerted by resveratrol, a component of grapes with important antioxidant properties [278]. Future studies should investigate whether treatments with "antiaging" properties may be beneficial to patients with AnxDs with hallmarks of accelerated aging and neuroprogression.

\section{Conflict of Interests}

The authors declare that there is no conflict of interests regarding the publication of this paper.

\section{References}

[1] J. M. Somers, E. M. Goldner, P. Waraich, and L. Hsu, "Prevalence and incidence studies of anxiety disorders: a systematic review of the literature," Canadian Journal of Psychiatry, vol. 51, no. 2, pp. 100-113, 2006.

[2] S. L. Blay and V. Marinho, "Anxiety disorders in old age," Current Opinion in Psychiatry, vol. 25, no. 6, pp. 462-467, 2012.

[3] E. J. Lenze and J. L. Wetherell, "A lifespan view of anxiety disorders," Dialogues in Clinical Neuroscience, vol. 13, no. 4, pp. 381-399, 2011.

[4] A. J. Flint and S. L. Rifat, "Relationship between clinical variables and symptomatic anxiety in late-life depression," American Journal of Geriatric Psychiatry, vol. 10, no. 3, pp. 292296, 2002.

[5] C. Andreescu and D. Varon, "New research on anxiety disorders in the elderly and an update on evidence-based treatments," Current Psychiatry Reports, vol. 17, no. 7, article 53, 2015.

[6] P. J. Tully, S. M. Cosh, and B. T. Baune, "A review of the affects of worry and generalized anxiety disorder upon cardiovascular health and coronary heart disease," Psychology, Health and Medicine, vol. 18, no. 6, pp. 627-644, 2013.

[7] P. P. Roy-Byrne, K. W. Davidson, R. C. Kessler et al., "Anxiety disorders and comorbid medical illness," General Hospital Psychiatry, vol. 30, no. 3, pp. 208-225, 2008.

[8] O. Potvin, C. Hudon, M. Dion, S. Grenier, and M. Préville, "Anxiety disorders, depressive episodes and cognitive impairment 
no dementia in community-dwelling older men and women," International Journal of Geriatric Psychiatry, vol. 26, no. 10, pp. 1080-1088, 2011.

[9] S. A. Beaudreau and R. O'Hara, "Late-life anxiety and cognitive impairment: a review," The American Journal of Geriatric Psychiatry, vol. 16, no. 10, pp. 790-803, 2008.

[10] S. A. Beaudreau and R. O'Hara, “The association of anxiety and depressive symptoms with cognitive performance in community-dwelling older adults," Psychology and Aging, vol. 24, no. 2, pp. 507-512, 2009.

[11] B. P. Yochim, A. E. Mueller, and D. L. Segal, "Late life anxiety is associated with decreased memory and executive functioning in community dwelling older adults," Journal of Anxiety Disorders, vol. 27, no. 6, pp. 567-575, 2013.

[12] M. Berk, F. Kapczinski, A. C. Andreazza et al., "Pathways underlying neuroprogression in bipolar disorder: focus on inflammation, oxidative stress and neurotrophic factors," Neuroscience and Biobehavioral Reviews, vol. 35, no. 3, pp. 804-817, 2011.

[13] P. M. Greenwood and R. Parasuraman, "Neuronal and cognitive plasticity: a neurocognitive framework for ameliorating cognitive aging," Frontiers in Aging Neuroscience, vol. 2, article 150, 2010.

[14] D. R. Riddle and R. J. Lichtenwalner, "Neurogenesis in the adult and aging brain," in Brain Aging: Models, Methods, and Mechanisms, D. R. Riddle, Ed., chapter 6, CRC Press, Boca Raton, Fla, USA, 2007.

[15] A. Pascual-Leone, C. Freitas, L. Oberman et al., "Characterizing brain cortical plasticity and network dynamics across the agespan in health and disease with TMS-EEG and TMS-fMRI, Brain Topography, vol. 24, no. 3-4, pp. 302-315, 2011.

[16] S. Moylan, M. Maes, N. R. Wray, and M. Berk, "The neuroprogressive nature of major depressive disorder: pathways to disease evolution and resistance, and therapeutic implications," Molecular Psychiatry, vol. 18, no. 5, pp. 595-606, 2013.

[17] B. Leonard and M. Maes, "Mechanistic explanations how cellmediated immune activation, inflammation and oxidative and nitrosative stress pathways and their sequels and concomitants play a role in the pathophysiology of unipolar depression," Neuroscience \& Biobehavioral Reviews, vol. 36, no. 2, pp. 764785, 2012.

[18] S. Moylan, M. Berk, O. M. Dean et al., "Oxidative \& nitrosative stress in depression: why so much stress?” Neuroscience and Biobehavioral Reviews, vol. 45, pp. 46-62, 2014.

[19] M. Vaváková, Z. Ďuračková, and J. Trebatická, "Markers of oxidative stress and neuroprogression in depression disorder," Oxidative Medicine and Cellular Longevity, vol. 2015, Article ID 898393, 12 pages, 2015.

[20] J. E. Verhoeven, D. Révész, P. van Oppen, E. S. Epel, O. M. Wolkowitz, and B. W. Penninx, "Anxiety disorders and accelerated cellular ageing," The British Journal of Psychiatry, vol. 206, no. 5, pp. 371-378, 2015.

[21] American Psychiatric Association, Diagnostic and Statistical Manual of Mental Disorders, American Psychiatric Association, Washington, DC, USA, 5th edition, 2013.

[22] K. L. Spalding, O. Bergmann, K. Alkass et al., "Dynamics of hippocampal neurogenesis in adult humans," Cell, vol. 153, no. 6, pp. 1219-1227, 2013.

[23] A. Ernst, K. Alkass, S. Bernard et al., "Neurogenesis in the striatum of the adult human brain," Cell, vol. 156, no. 5, pp. 10721083, 2014.
[24] O. Bergmann, J. Liebl, S. Bernard et al., "The age of olfactory bulb neurons in humans," Neuron, vol. 74, no. 4, pp. 634-639, 2012.

[25] B. R. Miller and R. Hen, "The current state of the neurogenic theory of depression and anxiety," Current Opinion in Neurobiology, vol. 30, pp. 51-58, 2015.

[26] C. Mirescu, J. D. Peters, and E. Gould, "Early life experience alters response of adult neurogenesis to stress," Nature Neuroscience, vol. 7, no. 8, pp. 841-846, 2004.

[27] G. P. Dias, M. C. Bevilaqua, A. C. da Luz et al., "Hippocampal biomarkers of fear memory in an animal model of generalized anxiety disorder," Behavioural Brain Research, vol. 263, pp. 3445, 2014.

[28] M. Bergami, R. Rimondini, S. Santi, R. Blum, M. Götz, and M. Canossa, "Deletion of TrkB in adult progenitors alters newborn neuron integration into hippocampal circuits and increases anxiety-like behavior," Proceedings of the National Academy of Sciences of the United States of America, vol. 105, no. 40, pp. 15570-15575, 2008.

[29] J.-M. Revest, D. Dupret, M. Koehl et al., "Adult hippocampal neurogenesis is involved in anxiety-related behaviors," Molecular Psychiatry, vol. 14, no. 10, pp. 959-967, 2009.

[30] T. Nakashiba, J. D. Cushman, K. A. Pelkey et al., "Young dentate granule cells mediate pattern separation, whereas old granule cells facilitate pattern completion," Cell, vol. 149, no. 1, pp. 188201, 2012.

[31] M. A. Kheirbek, K. C. Klemenhagen, A. Sahay, and R. Hen, "Neurogenesis and generalization: a new approach to stratify and treat anxiety disorders," Nature Neuroscience, vol. 15, no. 12, pp. 1613-1620, 2012.

[32] A. Surget, A. Tanti, E. D. Leonardo et al., "Antidepressants recruit new neurons to improve stress response regulation," Molecular Psychiatry, vol. 16, no. 12, pp. 1177-1188, 2011.

[33] D. J. David, B. A. Samuels, Q. Rainer et al., "Neurogenesisdependent and -independent effects of fluoxetine in an animal model of anxiety/depression," Neuron, vol. 62, no. 4, pp. 479493, 2009.

[34] A. S. Hill, A. Sahay, and R. Hen, "Increasing adult hippocampal neurogenesis is sufficient to reduce anxiety and depression-like behaviors," Neuropsychopharmacology, vol. 40, no. 10, pp. 23682378, 2015.

[35] T. D. Perera, A. J. Dwork, K. A. Keegan et al., "Necessity of hippocampal neurogenesis for the therapeutic action of antidepressants in adult Nonhuman primates," PLoS ONE, vol. 6, no. 4, Article ID e17600, 2011.

[36] N. F. Ho, J. M. Hooker, A. Sahay, D. J. Holt, and J. L. Roffman, "In vivo imaging of adult human hippocampal neurogenesis: progress, pitfalls and promise," Molecular Psychiatry, vol. 18, no. 4, pp. 404-416, 2013.

[37] L. N. Manganas, X. Zhang, Y. Li et al., "Magnetic resonance spectroscopy identifies neural progenitor cells in the live human brain," Science, vol. 318, no. 5852, pp. 980-985, 2007.

[38] C. Faravelli, C. Lo Sauro, L. Lelli et al., "The role of life events and HPA axis in anxiety disorders: a review," Current Pharmaceutical Design, vol. 18, no. 35, pp. 5663-5674, 2012.

[39] A. O’Donovan, B. M. Hughes, G. M. Slavich et al., "Clinical anxiety, cortisol and interleukin-6: evidence for specificity in emotion-biology relationships," Brain, Behavior, and Immunity, vol. 24, no. 7, pp. 1074-1077, 2010. 
[40] S. Suliman, S. M. Hemmings, and S. Seedat, "Brain-Derived Neurotrophic Factor (BDNF) protein levels in anxiety disorders: systematic review and meta-regression analysis," Frontiers in Integrative Neuroscience, vol. 7, article 55, 2013.

[41] L. Varela-Nallar, F. C. Aranguiz, A. C. Abbott, P. G. Slater, and N. C. Inestrosa, "Adult hippocampal neurogenesis in aging and Alzheimer's disease," Birth Defects Research Part C-Embryo Today: Reviews, vol. 90, no. 4, pp. 284-296, 2010.

[42] F. Calabrese, A. C. Rossetti, G. Racagni, P. Gass, M. A. Riva, and R. Molteni, "Brain-derived neurotrophic factor: a bridge between inflammation and neuroplasticity," Frontiers in Cellular Neuroscience, vol. 8, article 430, 2014.

[43] A. Olariu, K. M. Cleaver, and H. A. Cameron, "Decreased neurogenesis in aged rats results from loss of granule cell precursors without lengthening of the cell cycle," Journal of Comparative Neurology, vol. 501, no. 4, pp. 659-667, 2007.

[44] J. M. Barker, J. M. Wojtowicz, and R. Boonstra, "Where's my dinner? Adult neurogenesis in free-living food-storing rodents," Genes, Brain and Behavior, vol. 4, no. 2, pp. 89-98, 2005.

[45] C. T. Siwak-Tapp, E. Head, B. A. Muggenburg, N. W. Milgram, and C. W. Cotman, "Neurogenesis decreases with age in the canine hippocampus and correlates with cognitive function," Neurobiology of Learning and Memory, vol. 88, no. 2, pp. 249259, 2007.

[46] B. Leuner, Y. Kozorovitskiy, C. G. Gross, and E. Gould, "Diminished adult neurogenesis in the marmoset brain precedes old age," Proceedings of the National Academy of Sciences of the United States of America, vol. 104, no. 43, pp. 17169-17173, 2007.

[47] J. Nacher, G. Alonso-Llosa, D. R. Rosell, and B. S. McEwen, "NMDA receptor antagonist treatment increases the production of new neurons in the aged rat hippocampus," Neurobiology of Aging, vol. 24, no. 2, pp. 273-284, 2003.

[48] H. G. Kuhn, H. Dickinson-Anson, and F. H. Gage, "Neurogenesis in the dentate gyrus of the adult rat: age-related decrease of neuronal progenitor proliferation," The Journal of Neuroscience, vol. 16, no. 6, pp. 2027-2033, 1996.

[49] V. M. Heine, S. Maslam, M. Joëls, and P. J. Lucassen, "Increased P27KIP1 protein expression in the dentate gyrus of chronically stressed rats indicates $\mathrm{G}_{1}$ arrest involvement," Neuroscience, vol. 129, no. 3, pp. 593-601, 2004.

[50] L. K. Hamilton, S. E. Joppé, L. M. Cochard, and K. J. L. Fernandes, "Aging and neurogenesis in the adult forebrain: what we have learned and where we should go from here," European Journal of Neuroscience, vol. 37, no. 12, pp. 1978-1986, 2013.

[51] N. S. Burghardt, E. H. Park, R. Hen, and A. A. Fenton, "Adultborn hippocampal neurons promote cognitive flexibility in mice," Hippocampus, vol. 22, no. 9, pp. 1795-1808, 2012.

[52] O. Lazarov and M. P. Demars, "All in the family: how the apps regulate neurogenesis," Frontiers in Neuroscience, vol. 6, article 81, 2012.

[53] R. Kalisch, M. Schubert, W. Jacob et al., "Anxiety and hippocampus volume in the rat," Neuropsychopharmacology, vol. 31, no. 5, pp. 925-932, 2006.

[54] B. S. McEwen, "Effects of adverse experiences for brain structure and function," Biological Psychiatry, vol. 48, no. 8, pp. 721-731, 2000.

[55] F. Murray, D. W. Smith, and P. H. Hutson, "Chronic low dose corticosterone exposure decreased hippocampal cell proliferation, volume and induced anxiety and depression like behaviours in mice," European Journal of Pharmacology, vol. 583, no. 1, pp. 115-127, 2008.
[56] Y. Mikheenko, Y. Shiba, S. Sawiak et al., "Serotonergic, brain volume and attentional correlates of trait anxiety in primates," Neuropsychopharmacology, vol. 40, no. 6, pp. 1395-1404, 2015.

[57] J. N. Pannekoek, S. J. A. Van Der Werff, D. J. Stein, and N. J. A. Van Der Wee, "Advances in the neuroimaging of panic disorder," Human Psychopharmacology, vol. 28, no. 6, pp. 608-611, 2013.

[58] M. C. F. Ferrari, G. F. Busatto, P. K. McGuire, and J. A. S. Crippa, "Structural magnetic ressonance imaging in anxiety disorders: an update of research findings," Revista Brasileira de Psiquiatria, vol. 30, no. 3, pp. 251-264, 2008.

[59] K. Hilbert, U. Lueken, and K. Beesdo-Baum, "Neural structures, functioning and connectivity in Generalized Anxiety Disorder and interaction with neuroendocrine systems: a systematic review," Journal of Affective Disorders, vol. 158, pp. 114-126, 2014.

[60] P. Brambilla, G. Como, M. Isola et al., "White-matter abnormalities in the right posterior hemisphere in generalized anxiety disorder: a diffusion imaging study," Psychological Medicine, vol. 42, no. 2, pp. 427-434, 2012.

[61] V. Baur, J. Hänggi, M. Rufer et al., "White matter alterations in social anxiety disorder," Journal of Psychiatric Research, vol. 45, no. 10, pp. 1366-1372, 2011.

[62] A. Shimada and S. Hasegawa-Ishii, "Senescence-accelerated mice (SAMs) as a model for brain aging and immunosenescence," Aging and Disease, vol. 2, no. 5, pp. 414-435, 2011.

[63] A. M. Hedman, N. E. M. van Haren, H. G. Schnack, R. S. Kahn, and H. E. Hulshoff Pol, "Human brain changes across the life span: a review of 56 longitudinal magnetic resonance imaging studies," Human Brain Mapping, vol. 33, no. 8, pp. 1987-2002, 2012.

[64] A. M. Fjell, L. T. Westlye, H. Grydeland et al., "Critical ages in the life course of the adult brain: nonlinear subcortical aging," Neurobiology of Aging, vol. 34, no. 10, pp. 2239-2247, 2013.

[65] A. M. Fjell, L. T. Westlye, I. Amlien et al., "High consistency of regional cortical thinning in aging across multiple samples," Cerebral Cortex, vol. 19, no. 9, pp. 2001-2012, 2009.

[66] A. M. Fjell, K. B. Walhovd, C. Fennema-Notestine et al., "Oneyear brain atrophy evident in healthy aging," The Journal of Neuroscience, vol. 29, no. 48, pp. 15223-15231, 2009.

[67] A. M. Fjell, L. McEvoy, D. Holland, A. M. Dale, and K. B. Walhovd, "What is normal in normal aging? Effects of aging, amyloid and Alzheimer's disease on the cerebral cortex and the hippocampus," Progress in Neurobiology, vol. 117, pp. 20-40, 2014.

[68] A. M. Fjell, L. McEvoy, D. Holland, A. M. Dale, and K. B. Walhovd, "Brain changes in older adults at very low risk for Alzheimer's disease," The Journal of Neuroscience, vol. 33, no. 19, pp. 8237-8242, 2013.

[69] M. Bozzali, M. Cercignani, and C. Caltagirone, "Brain volumetrics to investigate aging and the principal forms of degenerative cognitive decline: a brief review," Magnetic Resonance Imaging, vol. 26, no. 7, pp. 1065-1070, 2008.

[70] D. Antonenko and A. Flöel, "Healthy aging by staying selectively connected: a mini-review," Gerontology, vol. 60, no. 1, pp. 3-9, 2014.

[71] D. H. Salat, "The declining infrastructure of the aging brain," Brain Connectivity, vol. 1, no. 4, pp. 279-293, 2011.

[72] W. Wen, W. Zhu, Y. He et al., "Discrete neuroanatomical networks are associated with specific cognitive abilities in old age," Journal of Neuroscience, vol. 31, no. 4, pp. 1204-1212, 2011.

[73] S. J. Broyd, C. Demanuele, S. Debener, S. K. Helps, C. J. James, and E. J. S. Sonuga-Barke, "Default-mode brain dysfunction 
in mental disorders: a systematic review," Neuroscience and Biobehavioral Reviews, vol. 33, no. 3, pp. 279-296, 2009.

[74] C. M. Sylvester, M. Corbetta, M. E. Raichle et al., "Functional network dysfunction in anxiety and anxiety disorders," Trends in Neurosciences, vol. 35, no. 9, pp. 527-535, 2012.

[75] A. Hahn, P. Stein, C. Windischberger et al., "Reduced restingstate functional connectivity between amygdala and orbitofrontal cortex in social anxiety disorder," NeuroImage, vol. 56, no. 3, pp. 881-889, 2011.

[76] M. J. Kim, D. G. Gee, R. A. Loucks, F. C. Davis, and P. J. Whalen, "Anxiety dissociates dorsal and ventral medial prefrontal cortex functional connectivity with the amygdala at rest," Cerebral Cortex, vol. 21, no. 7, pp. 1667-1673, 2011.

[77] C. Andreescu, L. K. Sheu, D. Tudorascu, S. Walker, and H. Aizenstein, "The ages of anxiety-differences across the lifespan in the default mode network functional connectivity in generalized anxiety disorder," International Journal of Geriatric Psychiatry, vol. 29, no. 7, pp. 704-712, 2014.

[78] Y. I. Sheline, M. E. Raichle, A. Z. Snyder et al., "Amyloid plaques disrupt resting state default mode network connectivity in cognitively normal elderly," Biological Psychiatry, vol. 67, no. 6, pp. 584-587, 2010.

[79] L. Geerligs, N. M. Maurits, R. J. Renken, and M. M. Lorist, "Reduced specificity of functional connectivity in the aging brain during task performance," Human Brain Mapping, vol. 35, no. 1, pp. 319-330, 2014.

[80] L. Geerligs, E. Saliasi, N. M. Maurits, and M. M. Lorist, "Compensation through increased functional connectivity: neural correlates of inhibition in old and young," Journal of Cognitive Neuroscience, vol. 24, no. 10, pp. 2057-2069, 2012.

[81] N. A. Dennis and R. Cabeza, "Age-related dedifferentiation of learning systems: an fMRI study of implicit and explicit learning," Neurobiology of Aging, vol. 32, no. 12, pp. 2318.e172318.e30, 2011.

[82] A. Salami, J. Eriksson, and L. Nyberg, "Opposing effects of aging on large-scale brain systems for memory encoding and cognitive control," The Journal of Neuroscience, vol. 32, no. 31, pp. 10749-10757, 2012.

[83] D. Vidal-Pineiro, C. Valls-Pedret, S. Fernandez-Cabello et al., "Decreased default mode network connectivity correlates with age-associated structural and cognitive changes," Frontiers in Aging Neuroscience, vol. 6, article 256, 2014.

[84] A. Hafkemeijer, J. van der Grond, and S. A. R. B. Rombouts, "Imaging the default mode network in aging and dementia," Biochimica et Biophysica Acta-Molecular Basis of Disease, vol. 1822, no. 3, pp. 431-441, 2012.

[85] J. S. Damoiseaux, C. F. Beckmann, E. J. S. Arigita et al., "Reduced resting-state brain activity in the 'default network' in normal aging," Cerebral Cortex, vol. 18, no. 8, pp. 1856-1864, 2008.

[86] J. R. Andrews-Hanna, A. Z. Snyder, J. L. Vincent et al., "Disruption of large-scale brain systems in advanced aging," Neuron, vol. 56, no. 5, pp. 924-935, 2007.

[87] D. Wang, X. Zhai, P. Chen et al., "Hippocampal UCP2 is essential for cognition and resistance to anxiety but not required for the benefits of exercise," Neuroscience, vol. 277, pp. 36-44, 2014.

[88] S. C. Heinrichs, M. P. Stenzel-Poore, L. H. Gold et al., "Learning impairment in transgenic mice with central overexpression of corticotropin-releasing factor," Neuroscience, vol. 74, no. 2, pp. 303-311, 1996.
[89] F. Ohl and E. Fuchs, "Memory performance in tree shrews: effects of stressful experiences," Neuroscience \& Biobehavioral Reviews, vol. 23, no. 2, pp. 319-323, 1998.

[90] M. A. Butters, R. K. Bhalla, C. Andreescu et al., "Changes in neuropsychological functioning following treatment for latelife generalised anxiety disorder," British Journal of Psychiatry, vol. 199, no. 3, pp. 211-218, 2011.

[91] J. Mohlman, R. B. Price, and J. Vietri, "Attentional bias in older adults: effects of generalized anxiety disorder and cognitive behavior therapy," Journal of Anxiety Disorders, vol. 27, no. 6, pp. 585-591, 2013.

[92] B. Croisile, E. Simon, J.-L. Astier, C. Beaumont, and H. Mollion, "The 5 -word test in 85 patients with generalized anxiety disorder," Presse Medicale, vol. 38, no. 11, pp. 1568-1576, 2009.

[93] A. E. Castaneda, J. Suvisaari, M. Marttunen et al., "Cognitive functioning in a population-based sample of young adults with anxiety disorders," European Psychiatry, vol. 26, no. 6, pp. 346353, 2011.

[94] E. P. Castillo, P. E. C. Coy, F. O. Shejet, E. T. Duran, and D. M. Cabrera, "Cognitive function evaluation: attention and memory in panic disorder patients," Salud Mental, vol. 33, no. 6, pp. 481488, 2010.

[95] M. Boldrini, L. Del Pace, G. P. A. Placidi et al., "Selective cognitive deficits in obsessive-compulsive disorder compared to panic disorder with agoraphobia," Acta Psychiatrica Scandinavica, vol. 111, no. 2, pp. 150-158, 2005.

[96] M. E. Coles and R. G. Heimberg, "Memory biases in the anxiety disorders: current status," Clinical Psychology Review, vol. 22, no. 4, pp. 587-627, 2002.

[97] A. E. Castaneda, A. Tuulio-Henriksson, M. Marttunen, J. Suvisaari, and J. Lönnqvist, "A review on cognitive impairments in depressive and anxiety disorders with a focus on young adults," Journal of Affective Disorders, vol. 106, no. 1-2, pp. 1-27, 2008.

[98] E. S. Becker, M. Andrich, W. T. Roth, and J. Margraf, "Explicit memory in anxiety disorders," Journal of Abnormal Psychology, vol. 108, no. 1, pp. 153-163, 1999.

[99] A. K. DeLuca, E. J. Lenze, B. H. Mulsant et al., "Comorbid anxiety disorder in late life depression: association with memory decline over four years," International Journal of Geriatric Psychiatry, vol. 20, no. 9, pp. 848-854, 2005.

[100] G. Sinoff and P. Werner, "Anxiety disorder and accompanying subjective memory loss in the elderly as a predictor of future cognitive decline," International Journal of Geriatric Psychiatry, vol. 18, no. 10, pp. 951-959, 2003.

[101] K. Palmer, A. K. Berger, R. Monastero, B. Winblad, L. Bäckman, and L. Fratiglioni, "Predictors of progression from mild cognitive impairment to Alzheimer disease," Neurology, vol. 68, no. 19, pp. 1596-1602, 2007.

[102] O. Potvin, H. Forget, S. Grenier, M. Préville, and C. Hudon, "Anxiety, depression, and 1-year incident cognitive impairment in community-dwelling older adults," Journal of the American Geriatrics Society, vol. 59, no. 8, pp. 1421-1428, 2011.

[103] N. A. Dennis, S. M. Hayes, S. E. Prince, D. J. Madden, S. A. Huettel, and R. Cabeza, "Effects of aging on the neural correlates of successful item and source memory encoding," Journal of Experimental Psychology: Learning Memory and Cognition, vol. 34, no. 4, pp. 791-808, 2008.

[104] T. M. Harrison, S. Weintraub, M.-M. Mesulam, and E. Rogalski, "Superior memory and higher cortical volumes in unusually successful cognitive aging," Journal of the International Neuropsychological Society, vol. 18, no. 6, pp. 1081-1085, 2012. 
[105] A. R. Kaup, H. Mirzakhanian, D. V. Jeste, and L. T. Eyler, "A review of the brain structure correlates of successful cognitive aging," Journal of Neuropsychiatry and Clinical Neurosciences, vol. 23, no. 1, pp. 6-15, 2011.

[106] A.-L. Sandu, R. T. Staff, C. J. McNeil et al., "Structural brain complexity and cognitive decline in late life-a longitudinal study in the Aberdeen 1936 Birth Cohort," NeuroImage, vol. 100, pp. 558-563, 2014.

[107] T. A. Salthouse and S. J. Czaja, "Structural constraints on process explanations in cognitive aging," Psychology and Aging, vol. 15, no. 1, pp. 44-55, 2000.

[108] D. Schretlen, G. D. Pearlson, J. C. Anthony et al., "Elucidating the contributions of processing speed, executive ability, and frontal lobe volume to normal age-related differences in fluid intelligence," Journal of the International Neuropsychological Society, vol. 6, no. 1, pp. 52-61, 2000.

[109] L. Nyberg, M. Lövdén, K. Riklund, U. Lindenberger, and L. Bäckman, "Memory aging and brain maintenance," Trends in Cognitive Sciences, vol. 16, no. 5, pp. 292-305, 2012.

[110] D. C. Park and P. Reuter-Lorenz, "The adaptive brain: aging and neurocognitive scaffolding," Annual Review of Psychology, vol. 60, pp. 173-196, 2009.

[111] C. L. Grady, M. V. Springer, D. Hongwanishkul, A. R. McIntosh, and G. Winocur, "Age-related changes in brain activity across the adult lifespan," Journal of Cognitive Neuroscience, vol. 18, no. 2, pp. 227-241, 2006.

[112] D. Puzzo and O. Arancio, "Amyloid- $\beta$ peptide: Dr. Jekyll or Mr. Hyde?” Journal of Alzheimer's Disease, vol. 33, supplement 1, pp. S111-S120, 2013.

[113] R. H. Takahashi, T. A. Milner, F. Li et al., "Intraneuronal Alzheimer $\mathrm{A} \beta 42$ accumulates in multivesicular bodies and is associated with synaptic pathology," The American Journal of Pathology, vol. 161, no. 5, pp. 1869-1879, 2002.

[114] B. Biscaro, O. Lindvall, C. Hock, C. T. Ekdahl, and R. M. Nitsch, "Abeta immunotherapy protects morphology and survival of adult-born neurons in doubly transgenic APP/PS1 mice," The Journal of Neuroscience, vol. 29, no. 45, pp. 14108-14119, 2009.

[115] K. N. Green, L. M. Billings, B. Roozendaal, J. L. McGaugh, and F. M. LaFerla, "Glucocorticoids increase amyloid-beta and tau pathology in a mouse model of Alzheimer's disease," The Journal of Neuroscience, vol. 26, no. 35, pp. 9047-9056, 2006.

[116] J.-E. Kang, J. R. Cirrito, H. Dong, J. G. Csernansky, and D. M. Holtzman, "Acute stress increases interstitial fluid amyloid$\beta$ via corticotropin-releasing factor and neuronal activity," Proceedings of the National Academy of Sciences of the United States of America, vol. 104, no. 25, pp. 10673-10678, 2007.

[117] C. Zussy, A. Brureau, B. Delair et al., "Time-course and regional analyses of the physiopathological changes induced after cerebral injection of an amyloid beta fragment in rats," The American Journal of Pathology, vol. 179, no. 1, pp. 315-334, 2011.

[118] A. Brureau, C. Zussy, B. Delair et al., "Deregulation of hypothalamic-pituitary-adrenal axis functions in an Alzheimer's disease rat model," Neurobiology of Aging, vol. 34, no. 5, pp. 1426-1439, 2013.

[119] H. Lavretsky, P. Siddarth, V. Kepe et al., "Depression and anxiety symptoms are associated with cerebral FDDNP-PET binding in middle-aged and older nondemented adults," American Journal of Geriatric Psychiatry, vol. 17, no. 6, pp. 493-502, 2009.

[120] I. H. G. B. Ramakers, F. R. J. Verhey, P. Scheltens et al., "Anxiety is related to Alzheimer cerebrospinal fluid markers in subjects with mild cognitive impairment," Psychological Medicine, vol. 43, no. 5, pp. 911-920, 2013.
[121] R. H. Pietrzak, J. C. Scott, A. Neumeister et al., "Anxiety symptoms, cerebral amyloid burden and memory decline in healthy older adults without dementia: 3-year prospective cohort study," British Journal of Psychiatry, vol. 204, no. 5, pp. 400-401, 2014.

[122] R. H. Pietrzak, Y. Y. Lim, A. Neumeister et al., "Amyloid- $\beta$, anxiety, and cognitive decline in preclinical Alzheimer disease: a multicenter, prospective cohort study," JAMA Psychiatry, vol. 72, no. 3, pp. 284-291, 2015.

[123] D. Norvin, G. Kim, A. Baker-Nigh, and C. Geula, "Accumulation and age-related elevation of amyloid-beta within basal forebrain cholinergic neurons in the rhesus monkey," Neuroscience, vol. 298, pp. 102-111, 2015.

[124] K. M. Rodrigue, K. M. Kennedy, M. D. Devous Sr. et al., "Betaamyloid burden in healthy aging: regional distribution and cognitive consequences," Neurology, vol. 78, no. 6, pp. 387-395, 2012.

[125] R. L. Buckner, A. Z. Snyder, B. J. Shannon et al., "Molecular, structural, and functional characterization of Alzheimer's disease: evidence for a relationship between default activity, amyloid, and memory," The Journal of Neuroscience, vol. 25, no. 34, pp. 7709-7717, 2005.

[126] C. C. Rowe, S. Ng, U. Ackermann et al., "Imaging beta-amyloid burden in aging and dementia," Neurology, vol. 68, no. 20, pp. 1718-1725, 2007.

[127] M. Storandt, M. A. Mintun, D. Head, and J. C. Morris, "Cognitive decline and brain volume loss as signatures of cerebral amyloid- $\beta$ peptide deposition identified with Pittsburgh compound B: cognitive decline associated with $\mathrm{A} \beta$ deposition," Archives of Neurology, vol. 66, no. 12, pp. 1476-1481, 2009.

[128] A. M. Fjell, K. B. Walhovd, C. Fennema-Notestine et al., "Brain atrophy in healthy aging is related to CSF levels of A $\beta 1-42$," Cerebral Cortex, vol. 20, no. 9, pp. 2069-2079, 2010.

[129] J. A. Becker, T. Hedden, J. Carmasin et al., "Amyloid-beta associated cortical thinning in clinically normal elderly," Annals of Neurology, vol. 69, no. 6, pp. 1032-1042, 2011.

[130] E. C. Mormino, J. T. Kluth, C. M. Madison et al., "Episodic memory loss is related to hippocampal-mediated $\beta$-amyloid deposition in elderly subjects," Brain, vol. 132, no. 5, pp. 13101323, 2009.

[131] K. E. Pike, G. Savage, V. L. Villemagne et al., "Beta-amyloid imaging and memory in non-demented individuals: evidence for preclinical Alzheimer's disease," Brain, vol. 130, part 11, pp. 2837-2844, 2007.

[132] S. Llado-Saz, M. Atienza, and J. L. Cantero, "Increased levels of plasma amyloid-beta are related to cortical thinning and cognitive decline in cognitively normal elderly subjects," Neurobiology of Aging, vol. 36, no. 10, pp. 2791-2797, 2015.

[133] W. Chen, M. Kimura, S. Kim et al., "Longitudinal versus crosssectional evaluations of leukocyte telomere length dynamics: age-dependent telomere shortening is the rule," Journals of Gerontology Series A: Biological Sciences and Medical Sciences, vol. 66, no. 3, pp. 312-319, 2011.

[134] Y.-F. Lee, S. Liu, N.-C. Liu et al., "Premature aging with impaired oxidative stress defense in mice lacking TR4," American Journal of Physiology -Endocrinology and Metabolism, vol. 301, no. 1, pp. E91-E98, 2011.

[135] P. G. Surtees, N. W. J. Wainwright, K. A. Pooley et al., "Life stress, emotional health, and mean telomere length in the European prospective investigation into cancer (EPIC)-Norfolk Population study," Journals of Gerontology Series A: Biological Sciences and Medical Sciences, vol. 66, no. 11, pp. 1152-1162, 2011. 
[136] E. S. Epel, E. H. Blackburn, J. Lin et al., "Accelerated telomere shortening in response to life stress," Proceedings of the National Academy of Sciences of the United States of America, vol. 101, no. 49, pp. 17312-17315, 2004.

[137] D. Révész, J. E. Verhoeven, Y. Milaneschi, E. J. C. N. De Geus, O. M. Wolkowitz, and B. W. J. H. Penninx, "Dysregulated physiological stress systems and accelerated cellular aging," Neurobiology of Aging, vol. 35, no. 6, pp. 1422-1430, 2014.

[138] O. I. Okereke, J. Prescott, J. Y. Y. Wong, J. Han, K. M. Rexrode, and I. de Vivo, "High phobic anxiety is related to lower leukocyte telomere length in women," PLOS ONE, vol. 7, no. 7, Article ID e40516, 2012.

[139] P. W. Hoen, J. G. M. Rosmalen, R. A. Schoevers, J. Huzen, P. Van Der Harst, and P. De Jonge, "Association between anxiety but not depressive disorders and leukocyte telomere length after 2 years of follow-up in a population-based sample," Psychological Medicine, vol. 43, no. 4, pp. 689-697, 2013.

[140] I. Shalev, T. E. Moffitt, A. W. Braithwaite et al., "Internalizing disorders and leukocyte telomere erosion: a prospective study of depression, generalized anxiety disorder and post-traumatic stress disorder," Molecular Psychiatry, vol. 19, no. 11, pp. 11631170, 2014.

[141] B. L. Needham, B. Mezuk, N. Bareis, J. Lin, E. H. Blackburn, and E. S. Epel, "Depression, anxiety and telomere length in young adults: evidence from the National Health and Nutrition Examination Survey," Molecular Psychiatry, vol. 20, no. 4, pp. 520-528, 2015.

[142] L. Kananen, I. Surakka, S. Pirkola et al., "Childhood adversities are associated with shorter telomere length at adult age both in individuals with an anxiety disorder and controls," PLOS ONE, vol. 5, no. 5, Article ID e10826, 2010.

[143] M. Armanios and E. H. Blackburn, "The telomere syndromes," Nature Reviews-Genetics, vol. 13, no. 10, pp. 693-704, 2012.

[144] B. B. de Jesus, K. Schneeberger, E. Vera, A. Tejera, C. B. Harley, and M. A. Blasco, "The telomerase activator TA-65 elongates short telomeres and increases health span of adult/old mice without increasing cancer incidence," Aging Cell, vol. 10, no. 4, pp. 604-621, 2011.

[145] S. Cohen, D. Janicki-Deverts, R. B. Turner et al., "Association between telomere length and experimentally induced upper respiratory viral infection in healthy adults," The Journal of the American Medical Association, vol. 309, no. 7, pp. 699-705, 2013.

[146] J. K. Kiecolt-Glaser, L. M. Jaremka, H. M. Derry, and R. Glaser, "Telomere length: a marker of disease susceptibility?" Brain, Behavior, and Immunity, vol. 34, pp. 29-30, 2013.

[147] C. B. Harley, W. Liu, M. Blasco et al., "A natural product telomerase activator as part of a health maintenance program," Rejuvenation Research, vol. 14, no. 1, pp. 45-56, 2011.

[148] C. B. Harley, W. Liu, P. L. Flom, and J. M. Raffaele, "A natural product telomerase activator as part of a health maintenance program: metabolic and cardiovascular response," Rejuvenation Research, vol. 16, no. 5, pp. 386-395, 2013.

[149] Z. Cai, L.-J. Yan, and A. Ratka, "Telomere shortening and Alzheimer's disease," NeuroMolecular Medicine, vol. 15, no. 1, pp. 25-48, 2013.

[150] S. E. Harris, C. Martin-Ruiz, T. von Zglinicki, J. M. Starr, and I. J. Deary, "Telomere length and aging biomarkers in 70-year-olds: the Lothian Birth Cohort 1936," Neurobiology of Aging, vol. 33, no. 7, pp. 1486.e3-1486.e8, 2012.

[151] S. L. Ma, E. S. S. Lau, E. W. C. Suen et al., “Telomere length and cognitive function in southern Chinese community-dwelling male elders," Age and Ageing, vol. 42, no. 4, pp. 450-455, 2013.
[152] M. Maes, "A review on the acute phase response in major depression," Reviews in the Neurosciences, vol. 4, no. 4, pp. 407416, 1993.

[153] J. K. Andersen, "Oxidative stress in neurodegeneration: cause or consequence?” Nature Medicine, vol. 10, supplement, pp. S18S25, 2004.

[154] R. Hou and D. S. Baldwin, "A neuroimmunological perspective on anxiety disorders," Human Psychopharmacology, vol. 27, no. 1, pp. 6-14, 2012.

[155] N. Salome, A. Tasiemski, I. Dutriez, A. Wigger, R. Landgraf, and O. Viltart, "Immune challenge induces differential corticosterone and interleukin- 6 responsiveness in rats bred for extremes in anxiety-related behavior," Neuroscience, vol. 151, no. 4, pp. 1112-1118, 2008.

[156] C. Song, A. G. Phillips, and B. Leonard, "Interleukin 1 beta enhances conditioned fear memory in rats: possible involvement of glucocorticoids," European Journal of Neuroscience, vol. 18, no. 7, pp. 1739-1743, 2003.

[157] J. Chen, Y. Song, J. Yang et al., "The contribution of TNF- $\alpha$ in the amygdala to anxiety in mice with persistent inflammatory pain," Neuroscience Letters, vol. 541, pp. 275-280, 2013.

[158] E. A. Hoge, K. Brandstetter, S. Moshier, M. H. Pollack, K. K. Wong, and N. M. Simon, "Broad spectrum of cytokine abnormalities in Panic disorder and posttraumatic stress disorder," Depression and Anxiety, vol. 26, no. 5, pp. 447-455, 2009.

[159] N. Vogelzangs, A. T. F. Beekman, P. De Jonge, and B. W. J. H. Penninx, "Anxiety disorders and inflammation in a large adult cohort," Translational Psychiatry, vol. 3, article e249, 2013.

[160] L. Foldager, O. Köhler, R. Steffensen et al., "Bipolar and panic disorders may be associated with hereditary defects in the innate immune system," Journal of Affective Disorders, vol. 164, pp. 148-154, 2014.

[161] J. D. Coplan, H. Tamir, D. Calaprice et al., "Plasma antiserotonin and serotonin anti-idiotypic antibodies are elevated in panic disorder," Neuropsychopharmacology, vol. 20, no. 4, pp. 386-391, 1999.

[162] C. Pitsavos, D. B. Panagiotakos, C. Papageorgiou, E. Tsetsekou, C. Soldatos, and C. Stefanadis, "Anxiety in relation to inflammation and coagulation markers, among healthy adults: the ATTICA study," Atherosclerosis, vol. 185, no. 2, pp. 320-326, 2006.

[163] G. Werner-Felmayer, E. R. Werner, D. Fuchs, A. Hausen, G. Reibnegger, and $\mathrm{H}$. Wachter, "Tumour necrosis factor-alpha and lipopolysaccharide enhance interferon-induced tryptophan degradation and pteridine synthesis in human cells," Biological Chemistry Hoppe-Seyler, vol. 370, no. 9, pp. 1063-1069, 1989.

[164] I. P. Lapin, L. G. Mutovkina, I. V. Ryzov, and S. Mirzaev, "Anxiogenic activity of quinolinic acid and kynurenine in the social interaction test in mice," Journal of Psychopharmacology, vol. 10, no. 3, pp. 246-249, 1996.

[165] A. Orlikov and I. Ryzov, "Caffeine-induced anxiety and increase of Kynurenine concentration in plasma of healthy subjects: a pilot study," Biological Psychiatry, vol. 29, no. 4, pp. 391-396, 1991.

[166] P. E. Wischmeyer, "Glutamine: role in gut protection in critical illness," Current Opinion in Clinical Nutrition and Metabolic Care, vol. 9, no. 5, pp. 607-612, 2006.

[167] E. Clark, C. Hoare, J. Tanianis-Hughes, G. L. Carlson, and G. Warhurst, "Interferon $\gamma$ induces translocation of commensal 
Escherichia coli across gut epithelial cells via a lipid raftmediated process," Gastroenterology, vol. 128, no. 5, pp. 12581267, 2005.

[168] Z. Sun, Å. Lasson, K. Olanders, X. Deng, and R. Andersson, "Gut barrier permeability, reticuloendothelial system function and protease inhibitor levels following intestinal ischaemia and reperfusion-effects of pretreatment with $\mathrm{N}$-acetyl-L-cysteine and indomethacin," Digestive and Liver Disease, vol. 34, no. 8, pp. 560-569, 2002.

[169] G. S. Bassi, A. Kanashiro, F. M. Santin, G. E. P. de Souza, M. J. Nobre, and N. C. Coimbra, "Lipopolysaccharide-induced sickness behaviour evaluated in different models of anxiety and innate fear in rats," Basic and Clinical Pharmacology and Toxicology, vol. 110, no. 4, pp. 359-369, 2012.

[170] T. J. Banasikowski, C. J. Cloutier, K. Ossenkopp, and M. Kavaliers, "Repeated exposure of male mice to low doses of lipopolysaccharide: dose and time dependent development of behavioral sensitization and tolerance in an automated lightdark anxiety test," Behavioural Brain Research, vol. 286, pp. 241248, 2015.

[171] C. G. Engeland, M. Kavaliers, and K.-P. Ossenkopp, "Sex differences in the effects of muramyl dipeptide and lipopolysaccharide on locomotor activity and the development of behavioral tolerance in rats," Pharmacology Biochemistry and Behavior, vol. 74, no. 2, pp. 433-447, 2003.

[172] J.-S. Grigoleit, J. S. Kullmann, O. T. Wolf et al., "Dose-dependent effects of endotoxin on neurobehavioral functions in humans," PLoS ONE, vol. 6, no. 12, Article ID e28330, 2011.

[173] K. Magnusson, L. Hauck, B. Jeffrey et al., "Relationships between diet-related changes in the gut microbiome and cognitive flexibility," Neuroscience, vol. 300, pp. 128-140, 2015.

[174] H. Engler, R. Doenlen, A. Engler et al., "Acute amygdaloid response to systemic inflammation," Brain, Behavior, and Immunity, vol. 25, no. 7, pp. 1384-1392, 2011.

[175] A. Salazar, B. L. Gonzalez-Rivera, L. Redus, J. M. Parrott, and J. C. O'Connor, "Indoleamine 2,3-dioxygenase mediates anhedonia and anxiety-like behaviors caused by peripheral lipopolysaccharide immune challenge," Hormones \& Behavior, vol. 62, no. 3, pp. 202-209, 2012.

[176] V. Pizza, A. Agresta, C. W. D’Acunto, M. Festa, and A. Capasso, "Neuroinflamm-aging and neurodegenerative diseases: an overview," CNS \& Neurological Disorders-Drug Targets, vol. 10, no. 5, pp. 621-634, 2011.

[177] J. M. Craft, D. M. Watterson, E. Hirsch, and L. J. Van Eldik, "Interleukin 1 receptor antagonist knockout mice show enhanced microglial activation and neuronal damage induced by intracerebroventricular infusion of human $\beta$-amyloid," Journal of Neuroinflammation, vol. 2, article 15, 2005.

[178] T. Jiang, J.-T. Yu, X.-C. Zhu et al., “Triggering receptor expressed on myeloid cells 2 knockdown exacerbates aging-related neuroinflammation and cognitive deficiency in senescenceaccelerated mouse prone 8 mice," Neurobiology of Aging, vol. 35, no. 6, pp. 1243-1251, 2014.

[179] T. Singh and A. B. Newman, "Inflammatory markers in population studies of aging," Ageing Research Reviews, vol. 10, no. 3 , pp. 319-329, 2011.

[180] R. M. Barrientos, M. M. Kitt, L. R. Watkins, and S. F. Maier, "Neuroinflammation in the normal aging hippocampus," Neuroscience, 2015.

[181] H.-K. Kuo, C.-J. Yen, C.-H. Chang, C.-K. Kuo, J.-H. Chen, and F. Sorond, "Relation of C-reactive protein to stroke, cognitive disorders, and depression in the general population: systematic review and meta-analysis," The Lancet Neurology, vol. 4, no. 6, pp. 371-380, 2005.

[182] K. Arfanakis, D. A. Fleischman, G. Grisot et al., "Systemic ystemic inflammation in non-demented elderly human subjects: brain microstructure and cognition," PLOS ONE, vol. 8, no. 8, Article ID e73107, 2013.

[183] C. L. Satizabal, Y. C. Zhu, B. Mazoyer, C. Dufouil, and C. Tzourio, "Circulating IL-6 and CRP are associated with MRI findings in the elderly: the 3C-Dijon Study," Neurology, vol. 78, no. 10, pp. 720-727, 2012.

[184] M. Fornage, Y. A. Chiang, E. S. Omeara et al., "Biomarkers of inflammation and MRI-defined small vessel disease of the brain: the cardiovascular health study," Stroke, vol. 39, no. 7, pp. 1952-1959, 2008

[185] G. Candore, M. Bulati, C. Caruso et al., "Inflammation, cytokines, immune response, apolipoprotein E, cholesterol, and oxidative stress in Alzheimer disease: therapeutic implications," Rejuvenation Research, vol. 13, no. 2-3, pp. 301-313, 2010.

[186] T. Rehman, "Role of the gut microbiota in age-related chronic inflammation," Endocrine, Metabolic and Immune Disorders Drug Targets, vol. 12, no. 4, pp. 361-367, 2012.

[187] U.-K. Hanisch, J. Neuhaus, W. Rowe et al., "Neurotoxic consequences of central long-term administration of interleukin-2 in rats," Neuroscience, vol. 79, no. 3, pp. 799-818, 1997.

[188] M. A. Robinson, Y. Veliz, J. Bergado et al., "Neuronal toxicity of human recombinant interleukin-2 in rats. Morphological and behavioral validation," Revista de Neurologia, vol. 25, no. 139, pp. 452-456, 1997.

[189] R. L. Djavadian, "Serotonin and neurogenesis in the hippocampal dentate gyrus of adult mammals," Acta Neurobiologiae Experimentalis, vol. 64, no. 2, pp. 189-200, 2004.

[190] R. Schwarcz, W. O. Whetsell Jr., and R. M. Mangano, "Quinolinic acid: an endogenous metabolite that produces axonsparing lesions in rat brain," Science, vol. 219, no. 4582, pp. 316318, 1983.

[191] L. Khaspekov, E. Kida, I. Victorov, and M. J. Mossakowski, "Neurotoxic effect induced by quinolinic acid in dissociated cell culture of mouse hippocampus," Journal of Neuroscience Research, vol. 22, no. 2, pp. 150-157, 1989.

[192] G. Garthwaite and J. Garthwaite, "Quinolinate mimics neurotoxic actions of N-methyl-D-aspartate in rat cerebellar slices," Neuroscience Letters, vol. 79, no. 1-2, pp. 35-39, 1987.

[193] P. A. Zunszain, C. Anacker, A. Cattaneo et al., "Interleukin-1 $\beta$ : a new regulator of the kynurenine pathway affecting human hippocampal neurogenesis," Neuropsychopharmacology, vol. 37, no. 4, pp. 939-949, 2012.

[194] S. M. Allan and N. J. Rothwell, "Inflammation in central nervous system injury," Philosophical Transactions of the Royal Society B: Biological Sciences, vol. 358, no. 1438, pp. 1669-1677, 2003.

[195] P. Thornton, E. Pinteaux, R. M. Gibson, S. M. Allan, and N. J. Rothwell, "Interleukin-1-induced neurotoxicity is mediated by glia and requires caspase activation and free radical release," Journal of Neurochemistry, vol. 98, no. 1, pp. 258-266, 2006.

[196] B. Viviani, F. Gardoni, S. Bartesaghi et al., "Interleukin-1 $\beta$ released by gp120 drives neural death through tyrosine phosphorylation and trafficking of NMDA receptors," Journal of Biological Chemistry, vol. 281, no. 40, pp. 30212-30222, 2006.

[197] J. W. Koo and R. S. Duman, "IL- $1 \beta$ is an essential mediator of the antineurogenic and anhedonic effects of stress," Proceedings of the National Academy of Sciences of the United States of America, vol. 105, no. 2, pp. 751-756, 2008. 
[198] C. Song and H. Wang, "Cytokines mediated inflammation and decreased neurogenesis in animal models of depression," Progress in Neuro-Psychopharmacology and Biological Psychiatry, vol. 35, no. 3, pp. 760-768, 2011.

[199] J. Y. Zou and F. T. Crews, "TNF $\alpha$ potentiates glutamate neurotoxicity by inhibiting glutamate uptake in organotypic brain slice cultures: neuroprotection by NF $\kappa$ B inhibition," Brain Research, vol. 1034, no. 1-2, pp. 11-24, 2005.

[200] Y. Pang, L. Campbell, B. Zheng, L. Fan, Z. Cai, and P. Rhodes, "Lipopolysaccharide-activated microglia induce death of oligodendrocyte progenitor cells and impede their development," Neuroscience, vol. 166, no. 2, pp. 464-475, 2010.

[201] P. Agostinho, R. A. Cunha, and C. Oliveira, "Neuroinflammation, oxidative stress and the pathogenesis of Alzheimer's disease," Current Pharmaceutical Design, vol. 16, no. 25, pp. 2766-2778, 2010.

[202] H. Aikata, H. Takaishi, Y. Kawakami et al., "Telomere reduction in human liver tissues with age and chronic inflammation," Experimental Cell Research, vol. 256, no. 2, pp. 578-582, 2000.

[203] O. M. Wolkowitz, S. H. Mellon, E. S. Epel et al., "Leukocyte telomere length in major depression: correlations with chronicity, inflammation and oxidative stress-preliminary findings," PLoS ONE, vol. 6, no. 3, Article ID e17837, 2011.

[204] G. Lenaz, C. Bovina, G. Formiggini, and G. P. Castelli, "Mitochondria, oxidative stress, and antioxidant defences," Acta Biochimica Polonica, vol. 46, no. 1, pp. 1-21, 1999.

[205] M. Maes, M. Kubera, I. Mihaylova et al., "Increased autoimmune responses against auto-epitopes modified by oxidative and nitrosative damage in depression: implications for the pathways to chronic depression and neuroprogression," Journal of Affective Disorders, vol. 149, no. 1-3, pp. 23-29, 2013.

[206] Y. Xu, C. Wang, J. J. Klabnik, and J. M. O’Donnell, “Novel therapeutic targets in depression and anxiety: antioxidants as a candidate treatment," Current Neuropharmacology, vol. 12, no. 2, pp. 108-119, 2014.

[207] I. Hovatta, J. Juhila, and J. Donner, "Oxidative stress in anxiety and comorbid disorders," Neuroscience Research, vol. 68, no. 4, pp. 261-275, 2010.

[208] S. Salim, N. Sarraj, M. Taneja, K. Saha, M. V. Tejada-Simon, and G. Chugh, "Moderate treadmill exercise prevents oxidative stress-induced anxiety-like behavior in rats," Behavioural Brain Research, vol. 208, no. 2, pp. 545-552, 2010.

[209] I. A. Alhaider, A. M. Aleisa, T. T. Tran, K. H. Alzoubi, and K. A. Alkadhi, "Chronic caffeine treatment prevents sleep deprivation-induced impairment of cognitive function and synaptic plasticity," Sleep, vol. 33, no. 4, pp. 437-444, 2010.

[210] C. Desrumaux, P.-Y. Risold, H. Schroeder et al., "Phospholipid transfer protein (PLTP) deficiency reduces brain vitamin E content and increases anxiety in mice," The FASEB Journal, vol. 19, no. 2, pp. 296-297, 2005.

[211] M. Maes, A. Christophe, E. Bosmans, A. Lin, and H. Neels, "In humans, serum polyunsaturated fatty acid levels predict the response of proinflammatory cytokines to psychologic stress," Biological Psychiatry, vol. 47, no. 10, pp. 910-920, 2000.

[212] C. Song, X. Li, B. E. Leonard, and D. F. Horrobin, "Effects of dietary $n-3$ or $n-6$ fatty acids on interleukin- $1 \beta$-induced anxiety, stress, and inflammatory responses in rats," The Journal of Lipid Research, vol. 44, no. 10, pp. 1984-1991, 2003.

[213] M. D. Filiou, Y. Zhang, L. Teplytska et al., "Proteomics and metabolomics analysis of a trait anxiety mouse model reveals divergent mitochondrial pathways," Biological Psychiatry, vol. 70, no. 11, pp. 1074-1082, 2011.
[214] A. Berry, F. Capone, M. Giorgio et al., "Deletion of the life span determinant $066^{\text {Shc }}$ prevents age-dependent increases in emotionality and pain sensitivity in mice," Experimental Gerontology, vol. 42, no. 1-2, pp. 37-45, 2007.

[215] M. Maes, C. Song, A. Lin et al., "The effects of psychological stress on humans: increased production of pro-inflammatory cytokines and a Th1-like response in stress-induced anxiety," Cytokine, vol. 10, no. 4, pp. 313-318, 1998.

[216] J. K. Kiecolt-Glaser, M. A. Belury, R. Andridge, W. B. Malarkey, and R. Glaser, "Omega-3 supplementation lowers inflammation and anxiety in medical students: a randomized controlled trial," Brain, Behavior, and Immunity, vol. 25, no. 8, pp. 1725-1734, 2011.

[217] M. Atmaca, E. Tezcan, M. Kuloglu, B. Ustundag, and H. Tunckol, "Antioxidant enzyme and malondialdehyde values in social phobia before and after citalopram treatment," European Archives of Psychiatry and Clinical Neuroscience, vol. 254, no. 4, pp. 231-235, 2004.

[218] M. Atmaca, M. Kuloglu, E. Tezcan, and B. Ustundag, "Antioxidant enzyme and malondialdehyde levels in patients with social phobia," Psychiatry Research, vol. 159, no. 1-2, pp. 95-100, 2008.

[219] M. Kuloglu, M. Atmaca, E. Tezcan, B. Ustundag, and S. Bulut, "Antioxidant enzyme and malondialdehyde levels in patients with panic disorder," Neuropsychobiology, vol. 46, no. 4, pp. 186189, 2002.

[220] M. A. Ersoy, S. Selek, H. Celik et al., "Role of oxidative and antioxidative parameters in etiopathogenesis and prognosis of panic disorder," International Journal of Neuroscience, vol. 118, no. 7, pp. 1025-1037, 2008.

[221] I. G. Gul, R. Karlidag, B. E. Cumurcu et al., "The effect of agoraphobia on oxidative stress in panic disorder," Psychiatry Investigation, vol. 10, no. 4, pp. 317-325, 2013.

[222] E. Guney, M. Fatih Ceylan, A. Tektas et al., "Oxidative stress in children and adolescents with anxiety disorders," Journal of Affective Disorders, vol. 156, pp. 62-66, 2014.

[223] M. C. Kaya, Y. Bez, I. F. Karababa et al., "Decreased serum sulphydryl levels as a sign of increased oxidative stress in generalized anxiety disorder," Psychiatry Investigation, vol. 10, no. 3, pp. 281-285, 2013.

[224] P. Hasty, J. Campisi, J. Hoeijmakers, H. Van Steeg, and J. Vijg, "Aging and genome maintenance: lessons from the mouse?" Science, vol. 299, no. 5611, pp. 1355-1359, 2003.

[225] R. Imai, K. Asai, J.-I. Hanai, and M. Takenaka, “Transgenic mice overexpressing glia maturation factor- $\beta$, an oxidative stress inducible gene, show premature aging due to Zmpste24 downregulation," Aging, vol. 7, no. 7, pp. 486-499, 2015.

[226] S.-Q. Zhang, W.-J. Cai, J.-H. Huang et al., "Icariin, a natural flavonol glycoside, extends healthspan in mice," Experimental Gerontology, vol. 69, pp. 226-235, 2015.

[227] S. Dixit, A. Bernardo, J. M. Walker et al., "Vitamin C deficiency in the brain impairs cognition, increases amyloid accumulation and deposition, and oxidative stress in APP/PSEN1 and normally aging mice," ACS Chemical Neuroscience, vol. 6, no. 4, pp. 570-581, 2015.

[228] D. Kapogiannis and M. P. Mattson, "Disrupted energy metabolism and neuronal circuit dysfunction in cognitive impairment and Alzheimer's disease," The Lancet Neurology, vol. 10, no. 2, pp. 187-198, 2011.

[229] C. Bourne, Ö. Aydemir, V. Balanzá-Martínez et al., "Neuropsychological testing of cognitive impairment in euthymic bipolar disorder: an individual patient data meta-analysis," Acta Psychiatrica Scandinavica, vol. 128, no. 3, pp. 149-162, 2013. 
[230] P. Palta, L. J. Samuel, E. R. Miller, and S. L. Szanton, “Depression and oxidative stress: results from a meta-analysis of observational studies," Psychosomatic Medicine, vol. 76, no. 1, pp. 12-19, 2014.

[231] J. Flatow, P. Buckley, and B. J. Miller, "Meta-analysis of oxidative stress in schizophrenia," Biological Psychiatry, vol. 74, no. 6, pp. 400-409, 2013.

[232] W. Kou, D. Luchtman, and C. Song, "Eicosapentaenoic acid (EPA) increases cell viability and expression of neurotrophin receptors in retinoic acid and brain-derived neurotrophic factor differentiated SH-SY5Y cells," European Journal of Nutrition, vol. 47, no. 2, pp. 104-113, 2008.

[233] F. Calon and G. Cole, "Neuroprotective action of omega-3 polyunsaturated fatty acids against neurodegenerative diseases: evidence from animal studies," Prostaglandins Leukotrienes and Essential Fatty Acids, vol. 77, no. 5-6, pp. 287-293, 2007.

[234] X.-W. Zhang, W.-S. Hou, M. Li, and Z.-Y. Tang, "Omega-3 fatty acids and risk of cognitive decline in the elderly: a metaanalysis of randomized controlled trials," Aging Clinical and Experimental Research, 2015.

[235] D. Harman, “The biologic clock: the mitochondria?" Journal of the American Geriatrics Society, vol. 20, no. 4, pp. 145-147, 1972.

[236] M. Maes, P. Galecki, Y. S. Chang, and M. Berk, "A review on the oxidative and nitrosative stress (O\&NS) pathways in major depression and their possible contribution to the (neuro)degenerative processes in that illness," Progress in Neuro-Psychopharmacology and Biological Psychiatry, vol. 35, no. 3, pp. 676-692, 2011.

[237] A. Wu, Z. Ying, and F. Gomez-Pinilla, "Dietary omega-3 fatty acids normalize BDNF levels, reduce oxidative damage, and counteract learning disability after traumatic brain injury in rats," Journal of Neurotrauma, vol. 21, no. 10, pp. 1457-1467, 2004.

[238] W. J. H. Koopman, L. G. J. Nijtmans, C. E. J. Dieteren et al., "Mammalian mitochondrial complex I: biogenesis, regulation, and reactive oxygen species generation," Antioxidants and Redox Signaling, vol. 12, no. 12, pp. 1431-1470, 2010.

[239] D. M. Kirby, K. J. Rennie, T. K. Smulders-Srinivasan et al., "Transmitochondrial embryonic stem cells containing pathogenic mtDNA mutations are compromised in neuronal differentiation," Cell Proliferation, vol. 42, no. 4, pp. 413-424, 2009.

[240] L. Petrozzi, G. Ricci, N. J. Giglioli, G. Siciliano, and M. Mancuso, "Mitochondria and neurodegeneration," Bioscience Reports, vol. 27, no. 1-3, pp. 87-104, 2007.

[241] E. Seppet, M. Gruno, A. Peetsalu et al., "Mitochondria and energetic depression in cell pathophysiology," International Journal of Molecular Sciences, vol. 10, no. 5, pp. 2252-2303, 2009.

[242] S. DiMauro and E. A. Schon, "Mitochondrial disorders in the nervous system," Annual Review of Neuroscience, vol. 31, pp. 91123, 2008.

[243] C. Matthews, I. Gorenne, S. Scott et al., "Vascular smooth muscle cells undergo telomere-based senescence in human atherosclerosis: effects of telomerase and oxidative stress," Circulation Research, vol. 99, no. 2, pp. 156-164, 2006.

[244] J. M. J. Houben, H. J. J. Moonen, F. J. van Schooten, and G. J. Hageman, "Telomere length assessment: biomarker of chronic oxidative stress?" Free Radical Biology and Medicine, vol. 44, no. 3, pp. 235-246, 2008.

[245] M. Arimon, S. Takeda, K. L. Post, S. Svirsky, B. T. Hyman, and O. Berezovska, "Oxidative stress and lipid peroxidation are upstream of amyloid pathology," Neurobiology of Disease, 2015.
[246] D. J. Bonda, X. Wang, G. Perry et al., "Oxidative stress in Alzheimer disease: a possibility for prevention," Neuropharmacology, vol. 59, no. 4-5, pp. 290-294, 2010.

[247] A. L. Metti, J. A. Cauley, A. B. Newman et al., "Plasma beta amyloid level and depression in older adults," The Journals of Gerontology Series A: Biological Sciences and Medical Sciences, vol. 68, no. 1, pp. 74-79, 2013.

[248] A. Piccinni, N. Origlia, A. Veltri et al., "Plasma $\beta$-amyloid peptides levels: a pilot study in bipolar depressed patients," Journal of Affective Disorders, vol. 138, no. 1-2, pp. 160-164, 2012.

[249] L. B. Rizzo, L. G. Costa, R. B. Mansur et al., "The theory of bipolar disorder as an illness of accelerated aging: implications for clinical care and research," Neuroscience and Biobehavioral Reviews, vol. 42, pp. 157-169, 2014.

[250] N. A. Andrews, M. Papakosta, and N. M. Barnes, "Discovery of novel anxiolytic agents-the trials and tribulations of preclinical models of anxiety," Neurobiology of Disease, vol. 61, pp. 72-78, 2014.

[251] A. O’Donovan, G. M. Slavich, E. S. Epel, and T. C. Neylan, "Exaggerated neurobiological sensitivity to threat as a mechanism linking anxiety with increased risk for diseases of aging," Neuroscience \& Biobehavioral Reviews, vol. 37, no. 1, pp. 96-108, 2013.

[252] C. Vida, E. M. González, and M. De la Fuente, "Increase of oxidation and inflammation in nervous and immune systems with aging and anxiety," Current Pharmaceutical Design, vol. 20, no. 29, pp. 4656-4678, 2014.

[253] E. Sibille, "Molecular aging of the brain, neuroplasticity, and vulnerability to depression and other brain-related disorders," Dialogues in Clinical Neuroscience, vol. 15, no. 1, pp. 53-65, 2013.

[254] B. J. Rawdin, S. H. Mellon, F. S. Dhabhar et al., "Dysregulated relationship of inflammation and oxidative stress in major depression," Brain, Behavior, and Immunity, vol. 31, pp. 143-152, 2013.

[255] C. L. Raison, A. S. Borisov, B. J. Woolwine, B. Massung, G. Vogt, and A. H. Miller, "Interferon-alpha effects on diurnal hypothalamic-pituitary-adrenal axis activity: relationship with proinflammatory cytokines and behavior," Molecular Psychiatry, vol. 15, no. 5, pp. 535-547, 2010.

[256] K. A. Yonkers, S. E. Bruce, I. R. Dyck, and M. B. Keller, "Chronicity, relapse, and illness-course of panic disorder, social phobia, and generalized anxiety disorder: findings in men and women from 8 years of follow-up," Depression and Anxiety, vol. 17, no. 3, pp. 173-179, 2003.

[257] I. Smaga, E. Niedzielska, M. Gawlik et al., "Oxidative stress as an etiological factor and a potential treatment target of psychiatric disorders. Part 2. Depression, anxiety, schizophrenia and autism," Pharmacological Reports, vol. 67, no. 3, pp. 569580, 2015.

[258] Q.-G. Zhou, Y. Hu, D.-L. Wu et al., "Hippocampal telomerase is involved in the modulation of depressive behaviors," Journal of Neuroscience, vol. 31, no. 34, pp. 12258-12269, 2011.

[259] M. Taler, O. Miron, I. Gil-Ad, and A. Weizman, "Neuroprotective and procognitive effects of sertraline: in vitro and in vivo studies," Neuroscience Letters, vol. 550, pp. 93-97, 2013.

[260] G. Richter-Levin and M. Segal, "Age-related cognitive deficits in rats are associated with a combined loss of cholinergic and serotonergic functions," Annals of the New York Academy of Sciences, vol. 695, pp. 254-257, 1993.

[261] S. Salim, M. Asghar, G. Chugh, M. Taneja, Z. Xia, and K. Saha, "Oxidative stress: a potential recipe for anxiety, hypertension 
and insulin resistance," Brain Research, vol. 1359, pp. 178-185, 2010.

[262] P. Arivazhagan and C. Panneerselvam, "Neurochemical changes related to ageing in the rat brain and the effect of DL-alphalipoic acid," Experimental Gerontology, vol. 37, no. 12, pp. 14891494, 2002.

[263] S. D. Khanzode, G. N. Dakhale, S. S. Khanzode, A. Saoji, and R. Palasodkar, "Oxidative damage and major depression: the potential antioxidant action of selective serotonin-re-uptake inhibitors," Redox Report, vol. 8, no. 6, pp. 365-370, 2003.

[264] M. Boldrini, R. Hen, M. D. Underwood et al., "Hippocampal angiogenesis and progenitor cell proliferation are increased with antidepressant use in major depression," Biological Psychiatry, vol. 72, no. 7, pp. 562-571, 2012.

[265] Y. I. Sheline, T. West, K. Yarasheski et al., "An antidepressant decreases CSF A $\beta$ production in healthy individuals and in transgenic AD mice," Science Translational Medicine, vol. 6, no. 236, Article ID 236re4, 2014.

[266] A. T. Ludlow, S. Witkowski, M. R. Marshall et al., "Chronic exercise modifies age-related telomere dynamics in a tissuespecific fashion," The Journals of Gerontology, Series A: Biological Sciences and Medical Sciences, vol. 67, no. 9, pp. 911-926, 2012.

[267] S. A. Wolf, A. Melnik, and G. Kempermann, "Physical exercise increases adult neurogenesis and telomerase activity, and improves behavioral deficits in a mouse model of schizophrenia," Brain, Behavior, and Immunity, vol. 25, no. 5, pp. 971-980, 2011.

[268] S. J. Colcombe, K. I. Erickson, P. E. Scalf et al., "Aerobic exercise training increases brain volume in aging humans," The Journals of Gerontology Series A: Biological Sciences and Medical Sciences, vol. 61, no. 11, pp. 1166-1170, 2006.

[269] D. E. Barnes, K. Yaffe, W. A. Satariano, and I. B. Tager, "A longitudinal study of cardiorespiratory fitness and cognitive function in healthy older adults," Journal of the American Geriatrics Society, vol. 51, no. 4, pp. 459-465, 2003.

[270] R. Ruscheweyh, C. Willemer, K. Krüger et al., "Physical activity and memory functions: an interventional study," Neurobiology of Aging, vol. 32, no. 7, pp. 1304-1319, 2011.

[271] M. E. McCrate and B. K. Kaspar, "Physical activity and neuroprotection in amyotrophic lateral sclerosis," NeuroMolecular Medicine, vol. 10, no. 2, pp. 108-117, 2008.

[272] O. I. Okereke, B. A. Rosner, D. H. Kim et al., "Dietary fat types and 4-year cognitive change in community-dwelling older women," Annals of Neurology, vol. 72, no. 1, pp. 124-134, 2012.

[273] I. Lourida, M. Soni, J. Thompson-Coon et al., "Mediterranean diet, cognitive function, and dementia: a systematic review," Epidemiology, vol. 24, no. 4, pp. 479-489, 2013.

[274] Y. Gu, J. A. Luchsinger, Y. Stern, and N. Scarmeas, "Mediterranean diet, inflammatory and metabolic biomarkers, and risk of Alzheimer's disease," Journal of Alzheimer's Disease, vol. 22, no. 2, pp. 483-492, 2010.

[275] J. A. Luchsinger, J. M. Noble, and N. Scarmeas, "Diet and Alzheimer's disease," Current Neurology and Neuroscience Reports, vol. 7, no. 5, pp. 366-372, 2007.

[276] F. N. Jacka, A. Mykletun, M. Berk, I. Bjelland, and G. S. Tell, "The association between habitual diet quality and the common mental disorders in community-dwelling adults: the Hordaland health study," Psychosomatic Medicine, vol. 73, no. 6, pp. 483490, 2011.

[277] F. N. Jacka, P. J. Kremer, M. Berk et al., "A prospective study of diet quality and mental health in adolescents," PLOS ONE, vol. 6, no. 9, Article ID e24805, 2011.
[278] F. Allam, A. T. Dao, G. Chugh et al., "Grape powder supplementation prevents oxidative stress-induced anxiety-like behavior, memory impairment, and high blood pressure in rats," Journal of Nutrition, vol. 143, no. 6, pp. 835-842, 2013. 

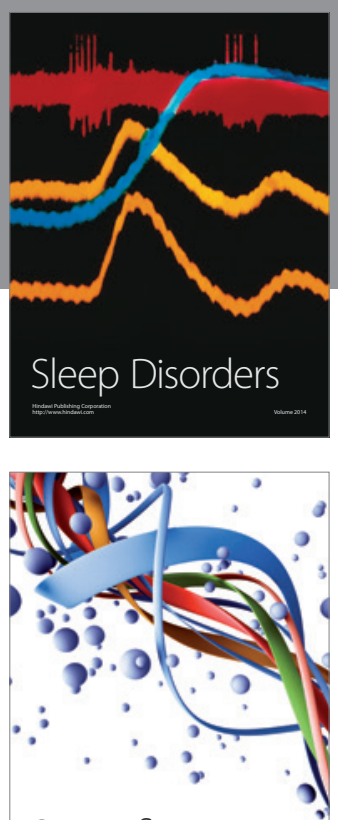

Scientifica
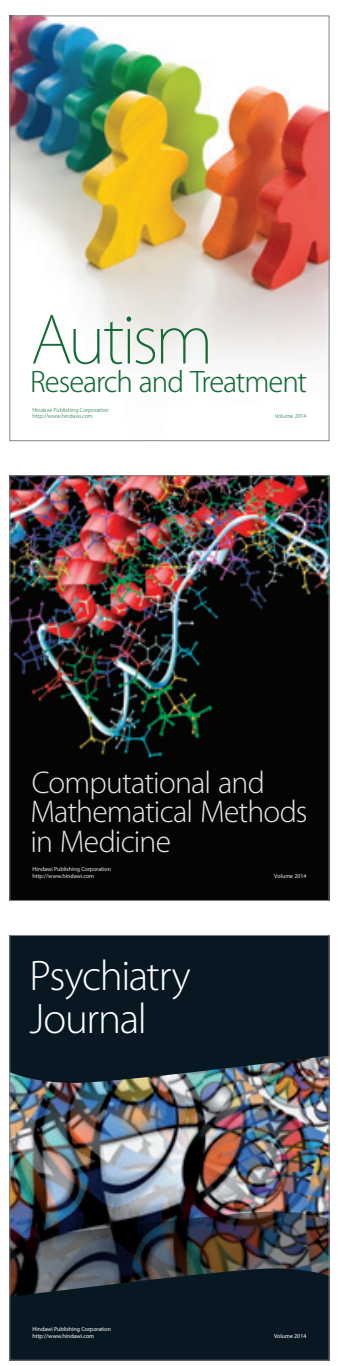
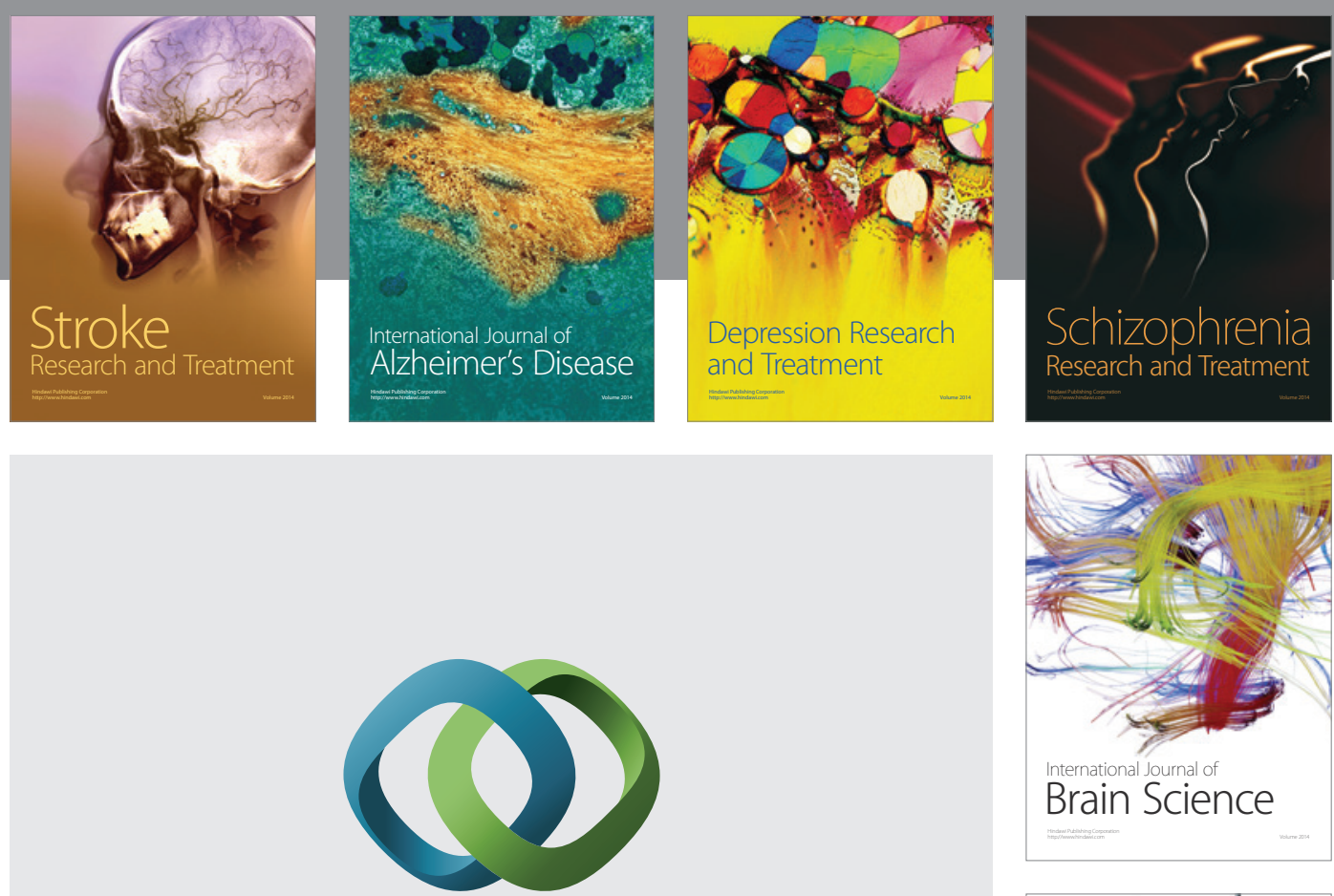

\section{Hindawi}

Submit your manuscripts at

http://www.hindawi.com
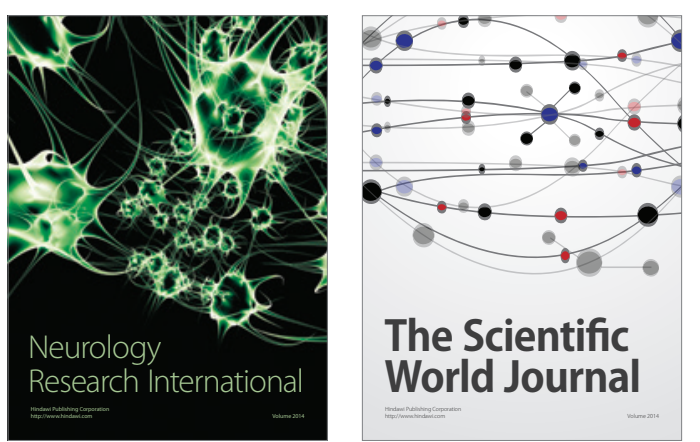

The Scientific World Journal

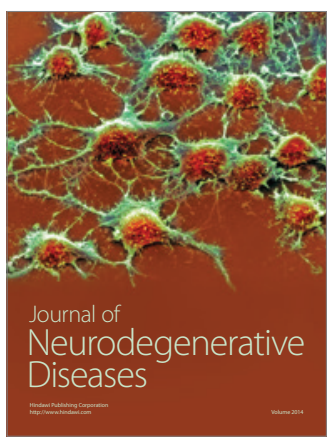

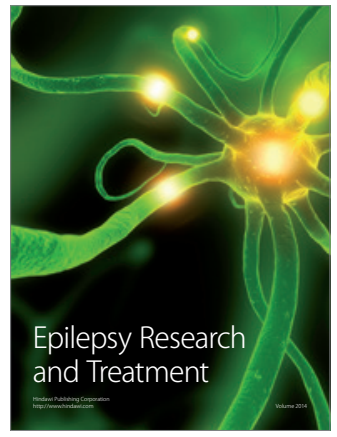

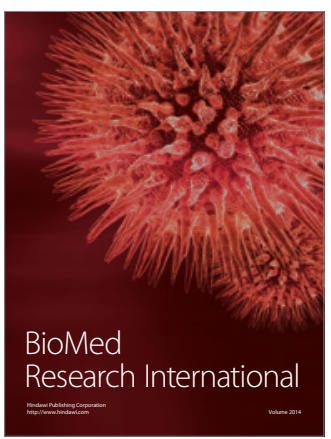

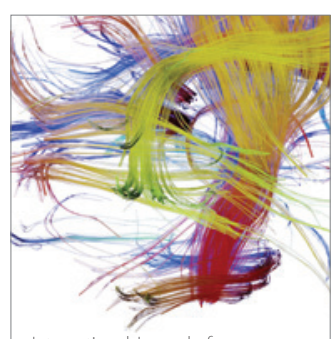

Brain Science

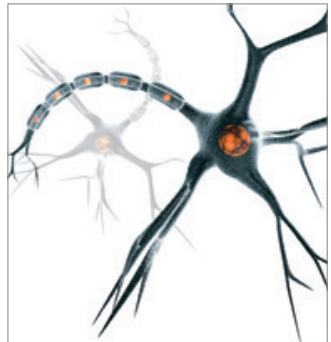

Neural Plasticity
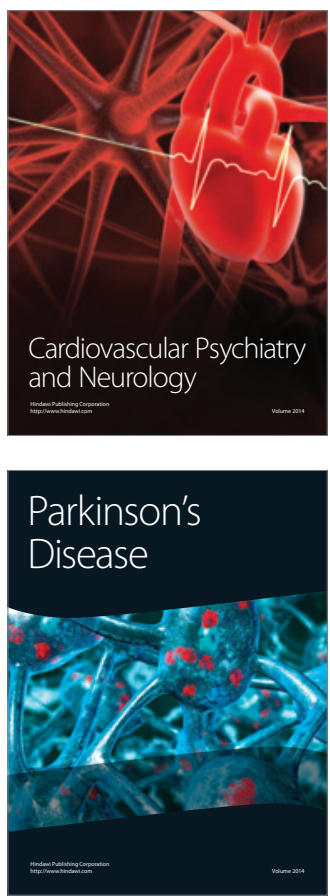